\title{
Data report: a downhole electrical resistivity study of northern Cascadia marine gas hydrate ${ }^{1}$
}

\author{
Marc-André P. Chen, ${ }^{2,3}$ Michael Riedel, ${ }^{4}$ George D. Spence, ${ }^{2}$ and Roy D. Hyndman ${ }^{2,3}$
}

\section{Chapter contents}

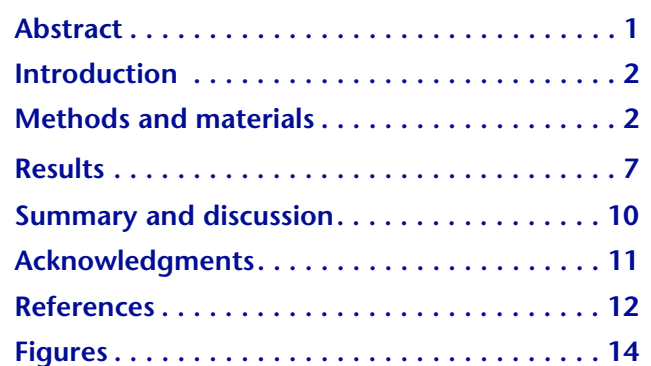

${ }^{1}$ Chen, M.-A.P., Riedel, M., Spence, G.D., and Hyndman, R.D., 2008. Data report: a downhole electrical resistivity study of northern Cascadia marine gas hydrate. In Riedel, M., Collett, T.S., Malone, M.J., and the Expedition 311 Scientists, Proc. IODP, 311: Washington, DC (Integrated Ocean Drilling Program Management International, Inc.).

doi:10.2204/iodp.proc.311.203.2008

${ }^{2}$ School of Earth and Ocean Sciences, University of Victoria, PO Box 3055 STN CSC, Victoria BC V8W 3P6, Canada.

${ }^{3}$ Geological Survey of Canada, Pacific Geoscience Centre, PO Box 6000, 9860 West Saanich Road, Sidney BC V8L 4B2, Canada.

${ }^{4}$ Department of Earth and Planetary Sciences, McGill University, 3450 University Street, Montréal QC H3A 2A7, Canada.

mriedel@eps.mcgill.ca

\section{Abstract}

Downhole electrical resistivity measurements can be exploited for gas hydrate concentration estimates. However, to do so requires that several assumptions be made, in particular about in situ pore water salinity and porosity. During Integrated Ocean Drilling Program Expedition 311, electrical resistivity was measured in four boreholes along a transect across the northern Cascadia margin, offshore Vancouver Island, Canada. Logging-while-drilling and conventional wireline logging data of resistivity, density, and neutron-porosity are used together with measurements of porosity and pore water salinity of the recovered core to systematically estimate gas hydrate concentrations at these four sites. Using Archie's law, empirical parameters $a$ and $m$ are determined from gas hydrate-free zones by means of a Pickett plot. The in situ salinity baseline trend for each site was estimated directly from the measured pore water salinity values, as well as indirectly by calculating the trend using Archie's law and simultaneously solving for gas hydrate saturation and in situ salinity. Results showed that the in situ salinities at Sites U1325, U1326, and U1329 were well determined from a smooth trend through the highest measured salinity values of the recovered core. Only Site U1327 exhibits strongly decreasing pore water salinity, reaching $22 \%$ at the base of the gas hydrate stability field. This regional low salinity requires special analyses to estimate gas hydrate concentration from resistivity and introduces a large uncertainty. It is suggested that the decreased salinity results largely (90\%) from a deeper fresh water source with the remaining freshening being the result of dissociation of pervasive gas hydrate ( $3 \%$ of the pore space). Considering estimates from density porosity to be the most accurate, gas hydrate saturations average $\sim 9 \% \pm 7 \%$ at Site U1326, $\sim 10 \% \pm 7 \%$ at Site U1325, and $11 \% \pm 7 \%$ at Site U1327 over the entire range of gas hydrate occurrence. No significant gas hydrate is inferred at Site U1329, although small amounts may be present just above the bottom-simulating reflector. In two localized zones at Site U1326 (60-100 mbsf [meters below seafloor]) and Site U1327 (120-150 mbsf), significantly higher gas hydrate concentrations of $>30 \%$ of the pore space were encountered. 


\section{Introduction}

Gas hydrate is a solid icelike substance consisting of a water lattice in which hydrocarbon molecules (most often methane) are embedded (Sloan, 1998). Marine gas hydrate generally occurs in the top few hundred meters of sediments in continental margins worldwide, especially in subduction zone accretionary prisms (e.g., Kvenvolden, 1993). Because gas hydrate has different physical properties than the pore fluid it commonly replaces (notably, its electrical resistivity and seismic velocity are significantly greater), its inclusion in the pore space of marine sediments can significantly affect the bulk physical properties of the sediment. Measurements of such properties can therefore provide a means to estimate gas hydrate concentration (e.g., Collett and Ladd, 2000; Yuan et al., 1996).

Gas hydrate is electrically resistive, to first approximation similar to the sediment matrix and in strong contrast to the conductive saline pore fluid it replaces. Therefore, as measured by resistivity, the effect of gas hydrate occurrence is, to first order, similar to that of replacing the pore fluid with matrixlike material (i.e., reducing the porosity). Based on this approximation, measurements of sediment resistivity and porosity can be used to estimate gas hydrate concentration. This assumption clearly breaks down if gas hydrate occurs massively in veins and fractures or sheets but may still provide an adequate approximation. The result of treating log resistivity with the porosity reduction in such cases is that the gas hydrate concentration is projected into the pore space and vertically smeared out because of the limited resolution of the logging tools used (as discussed later).

Several studies have made use of resistivity measurements (downhole and field) to estimate gas hydrate concentration, generally by employing Archie's (1942) relation to relate resistivity, porosity, and gas hydrate saturation (e.g., Pearson et al., 1983; Hyndman et al., 1999; Collett and Ladd, 2000; Yuan and Edwards, 2000; also see the "Expedition 311 summary" chapter). In this study, high-quality downhole log and core measurements are used to constrain gas hydrate occurrence, distribution, and concentration from electrical resistivity. The data were collected during Integrated Ocean Drilling Program (IODP) Expedition 311 (see the "Expedition 311 summary" chapter), offshore Vancouver Island, Canada, along a transect of four sites across the northern Cascadia accretionary prism (Fig. F1).

The estimates of gas hydrate concentrations reported in this paper are accompanied by a detailed uncertainty analyses. These have been achieved by systematically exploring the different data measurements available and by comparing results from different formulations of Archie's law. An emphasis is taken on the salinity background trend and its influence on the regional gas hydrate concentration estimates. Concentration estimates have been a long-debated topic, especially at Ocean Drilling Program (ODP) Leg 146 Site 889 prior to Expedition 311 (e.g., Hyndman et al., 1999; Riedel et al., 2005), as this location exhibits a strongly decreasing trend in pore water salinity down to bottom-simulating reflector (BSR) depths and remains constant below that level, which is unique compared to all others sites drilled during Expedition 311.

\section{Methods and materials}

\section{Archie's porosity-resistivity relation}

A basis for most rock resistivity studies was provided by Archie (1942), who examined the relation between resistivity and porosity in sandstone cores from the U.S. Gulf Coast region. We assume that this relation is an adequate approximation in all of our analyses. He empirically established that the resistivity of a fully water-saturated sediment $\left(R_{\mathrm{o}}\right)$ is closely proportional to the resistivity of the pore fluid $\left(R_{\mathrm{w}}\right)$ :

$$
R_{\mathrm{o}}=F R_{\mathrm{w}}
$$

where the proportionality constant $F$ is called the formation factor. Furthermore, by examining core samples from different formations, Archie established an exponential empirical relationship between $F$ and the porosity $(\varphi)$ :

$$
F=\frac{R_{\mathrm{o}}}{R_{\mathrm{w}}}=\varphi^{-\mathrm{m}}
$$

where the exponent $m$ was determined to be formation specific. Winsauer and Shearin (1952) modified Archie's original equation by including a coefficient $a$ in the relation:

$$
F=\frac{R_{\mathrm{o}}}{R_{\mathrm{w}}}=a \varphi^{-\mathrm{m}} .
$$

From a physical standpoint, $a$ should be unity, because when $\varphi=1, F=1$; however, because Equations 2 and 3 are empirical relations, allowing $a$ to vary generally improves the fit between $F$ and $\varphi$, as it provides an additional degree of freedom. From a physical perspective, the values of parameters $a$ and $m$ depend on the interconnectivity of the pore spaces, which in turn depends on lithology, cementation, and grain size distribution (Hearst et al., 2000). Smaller values of $a$ and $m$ are qualitatively indicative of well-interconnected pore spaces (i.e., lower $R_{\mathrm{o}}$ for a given $\varphi$ and $R_{\mathrm{w}}$ ). 
Many subsequent studies using downhole log data, core data, and laboratory measurements have confirmed the exponential relation to be a good approximation for relating resistivity to porosity (e.g., Jackson et al., 1978; Swanson, 1979; Hilfer, 1991; Ioannidis et al., 1997) and adequate for the purpose of this study.

\section{Effect of partial gas hydrate saturation}

When gas hydrate is formed from pore fluid, the salts in solution are largely excluded. The result is that the electrical resistivity of gas hydrate is much greater than that of saline pore fluid, and gas hydrate occurrence can significantly increase bulk sediment resistivity (e.g., Collett, 2001; Riedel et al., 2005). To first order, gas hydrate may be taken to be nonconductive (like the sediment grains) as compared to the pore fluid. An empirical relationship describes the effect of nonconductive material in the pore space on resistivity:

$$
R_{\mathrm{t}}=R_{\mathrm{o}} S_{\mathrm{w}}^{-\mathrm{n}}
$$

where $R_{\mathrm{t}}$ is the true or measured bulk resistivity, $S_{\mathrm{w}}$ is the water saturation (defined as the fraction of the pore space occupied by water), and $n$ is the saturation exponent (Hearst et al., 2000). In the case of partial gas hydrate pore space saturation, the gas hydrate saturation $\left(S_{\mathrm{h}}\right)$ is defined as $S_{\mathrm{h}}=1-S_{\mathrm{w}}$. The value of $n$ in Equation 4 is a measure of how the occurrence of gas hydrate affects $R_{\mathrm{o}}$ (i.e., the grainhydrate-fluid structure). If $n$ is relatively large, gas hydrate forms in a way that strongly impedes current flow and increases bulk sediment resistivity (e.g., gas hydrate located in the pore throats), whereas if $n$ is relatively small, gas hydrate forms in a way that has a lesser effect on sediment resistivity (e.g., gas hydrate occurrence in the pore space, making minimal contact with sediment grains). Pearson et al. (1983) calculated an estimate for $n$ of 1.94; however, modeling by Spangenberg (2001) has shown that $n$ depends somewhat on grain size distribution and the gas hydrate saturation itself. Combining Equations 3 and $\mathbf{4}$ gives Archie's relation for gas hydrate-bearing sediments (e.g., Collett and Ladd, 2000) as

$$
R_{\mathrm{t}}=a R_{\mathrm{w}} \varphi^{-\mathrm{m}}\left(1-S_{\mathrm{h}}\right)^{-\mathrm{n}} .
$$

In practice, for many marine sediments, the pore fluid resistivity $R_{\mathrm{w}}$ usually can be adequately estimated from the equation of state of seawater (Fofonoff, 1985), if in situ pressure, temperature, and salinity are known. Parameters $a$ and $m$ can be estimated empirically by curve fitting $F$ versus $\varphi$ data from fully water-saturated samples using Equation 3. Gas hydrate saturation can then be estimated for sediment with $\varphi$ and $R_{\mathrm{t}}$ if Equation 5 is rearranged as

$$
S_{\mathrm{h}}=1-\left[a \frac{R_{\mathrm{w}}}{R_{\mathrm{t}}} \varphi^{-\mathrm{m}}\right]^{\frac{1}{n}} .
$$

Equation provides a relationship between gas hydrate saturation and resistivity, that empirically accounts for the sediment porosity, the interconnectivity of the pore space, and the effect of gas hydrate occurrence on the interconnectivity of pore space. To estimate gas hydrate concentration from this relation requires measurements of $R_{\mathrm{t}}, \varphi$, and $R_{\mathrm{w}}$, as well as the estimation of empirical Archie parameters $a$, $m$, and $n$. The most important difficulty is estimating the in situ pore fluid salinity (i.e., pore fluid resistivity). The salinity measured in recovered cores could include an unknown amount of pore fluid freshening if in situ gas hydrate dissociates upon core recovery. One method, proposed by Hyndman et al. (1999), allows for in situ salinity and gas hydrate concentration to be calculated simultaneously but introduces additional uncertainties.

The approach taken in this study is to solve Archie's equation (Equation 6) to determine a gas hydrate saturation profile at each site of the drilling transect while quantifying the uncertainties in (1) the empirical Archie parameters, (2) the in situ salinity, and (3) the appropriate choice of porosity measurement, as well as their effect on gas hydrate saturation estimates.

\section{Log and core data}

Expedition 311 provided a suite of logging-whiledrilling (LWD) logs, including resistivity, density, and neutron porosity, in addition to several types of core measurements, including porosity, grain density, and interstitial water salinity (see the "Expedition 311 summary" chapter), along a transect of sites across the northern Cascadia accretionary prism. These data can be used jointly to solve Equation 6 for gas hydrate saturation. The use of LWD logs recorded by tools immediately behind the drill bit provides measurements as close as possible to in situ conditions. This is paramount in gas hydrate studies, because changes in pressure and temperature caused by drilling can affect gas hydrate stability locally around the borehole.

\section{Log resistivity}

Downhole formation electrical resistivity data have been obtained from both Expedition 311 and Leg 146 using both conventional wireline and LWD logging tools. The most reliable downhole resistivity measurement is obtained from the LWD geoVISION 
resistivity-at-the-bit (RAB) tool. The RAB tool is connected directly above the drill bit and uses two transmitter coils and several electrodes to obtain different measurements of resistivity. Resistivity is measured using a focusing technique: the upper and lower transmitter coils produce currents in the drill collar that meet at the ring electrode. In a homogeneous medium, a net current flow perpendicular to the tool would occur at the ring electrode. This radial current flow becomes distorted in heterogeneous formations, and the current required through the ring electrode to focus current flow into the formation is related to the formation resistivity (see the "Expedition 311 summary" chapter). This focusing technique is also used to measure resistivity at three button electrodes (corresponding to three depths of investigation: shallow $[\sim 0.3-0.4 \mathrm{~m}]$, medium $[\sim 0.4-$ $0.5 \mathrm{~m}]$, and deep [ 0.4-0.6 m]). As the tool rotates in the borehole, the button resistivity is measured every $\sim 6^{\circ}$. The button deep average (BDAV) resistivity, used here as $R_{\mathrm{t}}$ in the Archie analysis, is obtained by averaging the deep button resistivity at a given vertical depth over the range of azimuthally varying measurements. The BDAV resistivity has a vertical resolution of $5-8 \mathrm{~cm}$ and provides the most accurate measurement of in situ resistivity.

Figure F2A shows the BDAV resistivity profiles at the four Expedition 311 sites well transect. At each site, the seismically and log inferred base of gas hydrate stability zone or BSR depth is shown. Used alone, these resistivity logs qualitatively indicate certain zones of gas hydrate occurrence. High-porosity unconsolidated marine sediments in the study area generally have resistivities on the order of $1 \Omega \mathrm{m}$. Certain zones above the inferred BSR exhibit much higher resistivities and are therefore interpreted to be gas hydrate bearing, notably at Site U1326 at 73-94 meters below seafloor (mbsf) and 252-261 mbsf, at Site U1325 in thin layers between 195 and 240 mbsf, and at Site U1327 at 120-138 mbsf. The presence of gas hydrate near the BSR is inferred by a slight decrease in resistivity from 1.6 to $1.3 \Omega \mathrm{m}$ at Site U1325 and from 2.4 to $2.0 \Omega \mathrm{m}$ at Site U1327 across the BSR. Free gas immediately beneath the BSR might slightly increase the resistivity, explaining why no obvious decrease in resistivity at the BSR is observed at Sites U1326 and U1329. However, these two sites both exhibit thin high-resistivity zones immediately above the BSR (255-261 mbsf at Site U1326 and 120-124 mbsf at Site U1329), probably also related to gas hydrate occurrence. Therefore, all four sites probably exhibit at least a small amount of gas hydrate immediately above the BSR. The high-resistivity zone below 176 mbsf at Site U1329 is interpreted not to be gas hydrate but rather an unconformity, below which much older, low-porosity, lithified Miocene (>6.7 Ma) sediments occur (see the "Site U1329" chapter).

Figure F3 shows the suite of downhole resistivity data collected at Sites 889 and U1327. Holes 889A, 889B, and U1327E were logged with wireline induction tools, whereas Hole U1327A used LWD, with the BDAV resistivity shown here. The distance between Holes 889A, 889B, and Site U1327 is on the order of $500 \mathrm{~m}$, whereas the distance between Holes U1327A and U1327E is only $\sim 70 \mathrm{~m}$. The general trend observed in all holes at this site is an increase in resistivity from $\sim 1 \Omega \mathrm{m}$ at the seafloor to $\sim 2 \Omega \mathrm{m}$ at $\sim 120$ mbsf; background resistivities of $\sim 2 \Omega \mathrm{m}$ are observed below that depth, with thin higher resistivity zones at different depths at each site. The most dramatic variability between holes is actually between the two most spatially proximal holes (U1327A and U1327E), where consistently higher resistivities (by $\sim 0.3 \Omega \mathrm{m}$ ) were measured below $\sim 120 \mathrm{~m}$ in Hole U1327A, and a high resistivity interval ( $>5 \Omega \mathrm{m}$, between 120 and 138 mbsf) was measured only in Hole U1327A. The slight resistivity bias can possibly be explained by the use of different tools to log the hole or the different time lags between drilling and logging in LWD versus wireline. However, the observation of the high-resistivity zone (120-138 mbsf) only in Hole U1327A can only be explained by abrupt lateral lithologic variations, such as a confined turbidite deposit, and/or variations in gas hydrate occurrence, such as a steep vein or lens.

\section{Core porosity}

To first order, log and core porosity measurements generally account for gas hydrate as part of the pore space because properties that are measured to determine porosity are usually similar for gas hydrate and pore water. The available porosity measurements are from the density and neutron logs and from IODP shipboard core moisture and density (MAD) analyses after any gas hydrate has dissociated (Fig. F2B).

MAD-based core porosity was measured as one of the "index" properties on retrieved sediment cores by the Expedition 311 Scientists (see the "Expedition 311 summary" chapter). Wet mass, dry mass, and dry volume were measured on push-core samples of $\sim 10 \mathrm{~cm}^{3}$ to calculate porosity, as described in Blum (1997) and the "Methods" chapter. Wet mass was measured immediately after the sample was collected, whereas dry mass and volume were measured after the sample was heated at $105^{\circ} \pm 5^{\circ} \mathrm{C}$ (without vacuum) for $24 \mathrm{~h}$ and allowed to cool in a desiccator. Several biases in free water core porosity measurements must be corrected. There is a bias toward 
higher porosities because dry mass and volume were measured on sediments that had been heated to $105^{\circ} \mathrm{C}$, a temperature high enough to release some of the bound water in smectite clay (Winters, 2000). Although clays may be somewhat less resistive than the granular component of the sediment matrix, they are usually sufficiently resistive relative to the pore fluid to be included as part of the matrix in electrical resistivity analyses. Other corrections applied were for porosity rebound (Hamilton, 1976; Goldberg et al., 1986) and for residual salt left behind by the evaporated pore water (Blum, 1997). There is also a potential sampling bias toward lower porosities because porosity could be measured more frequently from more competent (generally less porous) core samples, which have a higher probability of recovery. Because gas hydrate dissociates into water and gas upon core recovery, porosity measurements from core MAD analysis measure in situ gas hydrate as part of the subsequent core pore volume.

\section{Log density porosity}

Log density-derived porosities are obtained from the LWD density log by linear interpolation of the formation bulk density $\left(\rho_{b}\right)$ between the density of water $\left(\rho_{w}\right)$, taken to be $1.03 \mathrm{~g} / \mathrm{cm}^{3}$, and the average grain density $\left(\rho_{g}\right)$ measured in the core MAD analysis:

$$
\varphi=\frac{\rho_{\mathrm{g}}-\rho_{\mathrm{b}}}{\rho_{\mathrm{g}}-\rho_{\mathrm{w}}} .
$$

An average grain density trend was estimated from core at each site, and values ranged from 2680 to $2780 \mathrm{~kg} / \mathrm{m}^{3}$. The variance in grain density measurements gave standard deviation estimates of 30 to 100 $\mathrm{kg} / \mathrm{m}^{3}$ that varied from site to site. Note that for the porosity estimate to exclude bound water, the average grain density must include the clay component of the sediment matrix. A log measurement of formation electron density is obtained based on the reduction in gamma ray flux between a source and a detector on the sonde. The source $\left({ }^{127} \mathrm{Cs}\right)$ emits gamma rays into the formation, which are then Compton-scattered by electrons in the formation. A fraction of the emitted gamma rays are scattered toward a gamma ray counter on the logging tool. The ratio of received to emitted gamma rays depends on the formation electron density, which is closely proportional to the formation bulk density because of the well-known relation between atomic number and atomic mass. High concentration of certain elements with unusual electron density responses can result in error (Hearst et al., 2000); however, this is not expected to be a problem given the composition of the sediments studied. The measurements are calibrated by empirically relating gamma ray count (i.e., formation bulk density) to core bulk density in a known reference.

The vertical resolution of the density tool used during Expedition 311 was $\sim 15 \mathrm{~cm}$, and the depth of investigation was $\sim 10 \mathrm{~cm}$. Even for LWD measurements, the density log must be excluded or used with caution in zones with poor hole conditions, especially where the hole radius is greater than the depth of investigation of the tool. These washout zones can be identified with the caliper tool. The main sources of uncertainty in a high-quality density porosity measurement are the statistical uncertainty in the gamma ray count used to calculate the density and the uncertainty in the grain density (discussed above). This combined uncertainty is estimated as \pm 0.03 porosity units (A. Malinverno, pers. comm., 2006). Because the density of pure gas hydrate $\left(\rho_{\mathrm{h}}=\right.$ $0.92)$ is similar to that of pore water $\left(\rho_{w}=1.03\right)$ with near seawater salinity, the density porosity calculated from Equation 7 measures gas hydrate nearly as part of the pore volume. Even at high gas hydrate concentrations, the assumption that water (instead of gas hydrate) fills the pore space has only a small effect on the calculated porosity (e.g., see the "Expedition 311 summary" chapter).

\section{Log neutron porosity}

The neutron porosity tool emits a high-energy neutron beam into the formation. As the neutrons pass through the formation, they interact with the ambient atoms, slow down, and are eventually captured. A lower energy neutron detector on the tool detects the neutrons that have been slowed by the formation (epithermal neutrons). Neutrons lose the most energy when they collide with atoms of similar mass, so the neutron tool is most sensitive to formation hydrogen concentration (Hearst et al., 2000) and therefore, to a first order, to water content. The ratio of emitted to detected neutrons is empirically related to porosity through calibration to a known reference, ideally with a similar response to that of the formation studied. Two factors known to cause significant errors in the neutron porosity measurement are fluid chlorinity and hydrocarbon content. The chlorine atom has an unusually large (neutron) capture cross section, but its effect can be accounted for if the chlorinity is known. In high enough concentrations, the presence of hydrocarbons can cause a positive bias in neutron porosity: because hydrocarbons represent a large amount of hydrogen, they can 
significantly increase the formation bulk hydrogen concentration if the other main hydrogen component is from the formation water content.

Clay minerals, when present in large enough concentration, can contain a significant amount of bound water that is measured by the neutron porosity tool as pore space, rather than sediment matrix. For this reason, in clay-rich sediments, porosity estimates from neutron logs are generally greater than those from density porosity (given a choice of average grain density in Equation 7 that includes clay). With knowledge of the clay content from cores, a correction for bound water content can be applied to the neutron log. The neutron porosity logs shown in Figure F2B have been corrected for bound water content by the Expedition 311 Scientists (see the "Expedition 311 summary" chapter) but still have a bias of $\sim 0.06-0.08$ greater porosity than the density porosity, probably caused by an incomplete correction for bound water content or other biases that were not adequately accounted for.

Core porosities generally are greater than log density porosities and less than log neutron porosities, but much closer to the density porosity than to the neutron. However, both the density and neutron porosity logs show similar structure, with more scatter in the neutron porosity. Because gas hydrate is mainly composed of (solid) water, it has a similar hydrogen concentration to that of water, so, to first order, the neutron porosity measures gas hydrate as part of the pore volume. However, both the methane in gas hydrate and the free gas below the BSR act to slightly increase the measured neutron porosity because methane has a greater hydrogen concentration than the pore water.

The vertical resolution of the neutron porosity tool used during Expedition 311 was $\sim 30 \mathrm{~cm}$. The depth of investigation into the borehole wall is highly dependent on the hydrogen concentration and is probably $<20 \mathrm{~cm}$, given the high-porosity sediments studied here. For both wireline and LWD measurements, neutron porosity is very sensitive to hole conditions.

\section{Determination of Archie parameters}

Archie's law for purely (saline) water-saturated sediments is given in Equation 3, where $R_{\mathrm{w}}$ can be calculated from the equation of state of seawater (Fofonoff, 1985) or other saline fluid compositions if the in situ pressure, temperature, and salinity are known. Pressure is taken to be nearly hydrostatic, temperature is estimated from the seafloor temperature and the thermal gradient, and salinity is taken from a smoothed fit through core salinity measurements at the same site (Fig. F4). In zones inferred to be gas hydrate-free (i.e., fully water saturated), the measured core salinity can be assumed to be equal to the in situ salinity. Empirical Archie parameters $a$ and $m$ can then be estimated from a crossplot of $F$ and $\varphi$ (Pickett plot) for sediments containing no gas hydrate in areas with good log quality. Gas hydratefree zones are chosen from the undeformed slope basin sediments of Holes U1327A and U1329A, where little or no gas hydrate was interpreted (i.e., no evidence in core and no large spikes in resistivity are observed). Also, slope basin sediments have less time to accumulate gas hydrate in the pore space because they were deposited more recently than the accreted sediments. Sediments below the inferred BSR in Holes U1325A, U1326A, and U1327A (Fig. F5) were also used. Although the sub-BSR zones probably contain a small amount of free gas, which could affect $R_{\mathrm{t}}$ and $\varphi$, these zones plot along the same trend in the Pickett plot as the assumed gas hydrate-free slope basin sediments, so the effect of free gas (in small concentrations) on Archie parameter estimates is small. Also, Hyndman et al. (1999) showed that porosity-resistivity relations in slope basin and accreted sediments are not significantly different.

Using all density porosity data and formation factor values from gas hydrate-free zones yields a cementation factor $m$ of 1.751 and $a$ is determined as 1.394 , very close to the earlier estimates by Westbrook, Carson, Musgrave, et al. (1994) and Hyndman et al. (1999). The $R^{2}$ value of the statistical fit to the data points is 0.82 . We therefore fix in this study the cementation factor $m$ to the original value of 1.76 determined for this part of the Cascadia margin for all calculations involving density porosity.

A best fit to the $F$ versus $\varphi$ data with the fixed $m$ value for the gas hydrate-free zones (Fig. F5) gives an estimate for $a$ of $1.38 \pm 0.18$ (one standard deviation), which is similar to the value obtained by Hyndman et al. (1999) from core porosity and resistivity at Site 889/890. Others (e.g., see the "Expedition 311 summary" chapter) have estimated Archie parameters by fixing $a$ to unity so that at $100 \%$ porosity $R_{\mathrm{w}}=R_{\mathrm{t}}$. Although this approach has a valid physical basis, fixing $m=1.76$ and searching for the best $a$ gives a better fit for these data. The uncertainty in the Archie relation arises mainly from the uncertainty in the Archie coefficient $a$. This uncertainty reflects the effect of data noise on the correlation between the porosity and resistivity measurements. Here, this includes random scatter (measurement error) in the density and resistivity logs, as well as error related to the average grain den- 
sity in the porosity calculation (Equation 7). An estimate of $n=1.94$, calculated by Pearson et al. (1983), is used here for the Archie saturation exponent. A sensitivity analysis of the saturation exponent shows that varying $n$ by \pm 0.20 changes the gas hydrate saturation estimate by only \pm 0.01 , on average. However, inspection of Equation 5 or $\mathbf{6}$ shows that gas hydrate saturation estimates themselves are more sensitive to $n$ at higher gas hydrate saturations. From a physical perspective, choosing a value for $n$ similar to that of $m$ implies the assumption that the effect of gas hydrate formation on the electrical resistivity is similar to that of simple effective porosity reduction.

\section{Results}

\section{Gas hydrate saturation from resistivity}

With estimated empirical Archie parameters $a, m$, and $n$, Equation 6 can be solved for $S_{\mathrm{h}}$. The critical unknown parameter in Archie's relation is the in situ $R_{\mathrm{w}}$, which can be calculated from the equation of state of seawater (Fofonoff, 1985) if the in situ pore water salinity is known, assuming that the pore fluid salt composition is similar to that of seawater. In gas hydrate-free zones, the in situ salinity can be taken as the measured core salinity. However, if gas hydrate was initially present in the core, it would have dissociated upon recovery, thereby freshening the pore water and contaminating the in situ salinity (Kastner et al., 1995; Hesse, 2003), which is the key parameter in determining $R_{\mathrm{w}}$. A lower estimated in situ salinity would result in a higher $R_{w}$, which in turn would erroneously reduce gas hydrate saturation estimates. The main difficulty is in estimating the in situ salinity before gas hydrate dissociation upon core recovery. In this paper, two methods are proposed to solve this problem. Each has advantages and limitations.

\section{Core baseline salinity method}

A first solution is to assume a reference no-hydrate salinity profile at each site, corresponding to the highest salinity measurements smoothed over depth (Fig. F4). This trend is referred to as the core baseline salinity $\left(C_{\mathrm{cb}}\right)$. In this case, lower-than-baseline core salinity measurements are assumed to be due to freshening by gas hydrate dissociation upon core recovery, and $C_{\mathrm{cb}}$ is used in the calculation of $R_{\mathrm{w}}$ from the equation of state of seawater (Fofonoff, 1985). This approach assumes that there is no pervasive gas hydrate present in the pore space, only local concentrations such as in sandier horizons (i.e., core salinity measurements sample considerable sections where the pore fluid has not been freshened by gas hydrate dissociation).

Once $R_{\mathrm{w}}$ has been calculated from $C_{\mathrm{cb}}$, a qualitative approach to identify gas hydrate zones is to compare $R_{\mathrm{t}}$ to the $R_{\mathrm{o}}$ that would have been measured if the sediment were fully water saturated (Fig. F6). $R_{\circ}$ is calculated from Equation 4, solved for $S_{\mathrm{h}}=0$. In Figure F6, zones above the BSR with $R_{\mathrm{t}}>R_{\mathrm{o}}$ are interpreted to contain gas hydrate.

To obtain quantitative estimates of gas hydrate saturation, $S_{\mathrm{h}}$ is calculated from Equation 6 (Fig. F7), with upper and lower bounds on $S_{\mathrm{h}}$ determined from the primary uncertainty associated with the estimated Archie coefficient $a$. In Figure F7, these results are smoothed by taking a running average over a 10 $\mathrm{m}$ interval. The uncertainty in the Archie coefficient $a$ accounts for an average estimated uncertainty in $S_{\mathrm{h}}$ of \pm 0.07 (one standard deviation).

The important systematic uncertainty in this method is related to the implicit assumption that $C_{\mathrm{cb}}$ is an accurate estimate of the in situ salinity. At most sites, this assumption is probably valid, because the core baseline salinity is near that of seawater (Fig. F4) (i.e., assuming that a gas hydrate-free core sample gives near-seawater salinity is generally reasonable). However, the core salinity measurements at Site U1327 exhibit an anomalous freshened baseline salinity trend relative to the other sites (and nearby cold vent Site U1328; see the "Site U1328" chapter) and therefore represent a special problem in interpretation. At Site U1327, the two end-member interpretations are that the pervasive freshening is either attributed to gas hydrate dissociation upon core recovery or to some other source of freshwater (e.g., rising fresh water from clay dehydration from deep within the accretionary prism). The core baseline salinity method attributes the regional freshening at Site U1327 (from seawater to baseline salinity) to sources other than gas hydrate dissociation. If all or most core samples were in fact freshened by pervasive gas hydrate, this regional gas hydrate would go undetected if the core baseline salinity method is used. The in situ salinity method can estimate pervasive gas hydrate contribution to core pore fluid freshening. However, it involves additional assumptions and uncertainties.

\section{In situ salinity method}

An alternative approach that makes no assumptions about in situ salinity is that of Hyndman et al. (1999). With additional assumptions, both gas hydrate saturation and in situ salinity can be estimated: 
they solve Archie's equation (Equation 6) for $S_{\mathrm{h}}$ simultaneously with

and

$$
R_{\mathrm{w}}=R_{\mathrm{sw}}\left(\frac{C_{\mathrm{sw}}}{C_{\mathrm{w}}}\right)
$$

$$
1-S_{\mathrm{h}}=\frac{C_{\text {core }}}{C_{\mathrm{w}}},
$$

where $R_{\mathrm{sw}}$ is the resistivity of seawater (dependent on pressure and temperature, but with fixed seawater salinity concentration $\left[C_{\mathrm{sw}}\right]$ taken to be 35$), C_{\text {core }}$ is the core fluid salinity concentration (after dissociation of any in situ gas hydrate), and $C_{\mathrm{w}}$ is the in situ fluid salinity, which is unknown. The physical basis for Equation 9 is the salinity dilution resulting from gas hydrate dissociation upon core recovery. Hyndman et al. (1999) assumed the simplification $n=m$; their equation is modified here to allow for different values of $n$ and $m$ (Riedel et al., 2005):

$$
S_{\mathrm{h}}=1-\left(\frac{a C_{\mathrm{sw}} R_{\mathrm{sw}}}{\varphi^{\mathrm{m}} C_{\text {core }} R_{\mathrm{t}}}\right)^{\frac{1}{(n-1)}},
$$

where $R_{\mathrm{t}}$ is the measured resistivity. For exactness, this calculation requires $C_{\text {core }}$ to be measured from the same physical sample in which resistivity was measured. However, the resistivity data is from nearby downhole logs (from a different hole at the same site). The best approximation available is to take $C_{\text {core }}$ as the $C_{\mathrm{cb}}$ trend. This is somewhat different from the approach of Hyndman et al. (1999), who had less data available. This yields the gas hydrate saturation profiles shown in Figure F8, averaged vertically, over a $10 \mathrm{~m}$ window. The in situ salinity method gives systematically higher gas hydrate saturation estimates than the core baseline salinity method but also exhibits a larger standard deviation.

Having solved for $S_{\mathrm{h}}$ in Equation 10, Equation 9 provides a means to calculate $C_{\mathrm{w}}$, which can then be compared to $C_{\mathrm{cb}}$ to determine if there is regional salinity dilution in the recovered core caused by pervasive gas hydrate occurrence (i.e., to determine whether the $C_{\mathrm{cb}}$ trend is a good estimate of $C_{\mathrm{w}}$ ) (Fig. F9). It is first observed that in areas with high gas hydrate saturation, $C_{\mathrm{w}}$ calculated by the in situ salinity method is much higher than $C_{\mathrm{cb}}$ and even reaches unreasonable amounts in some places. This occurs because $C_{\text {core }}$ is taken in Equation 10 to be the $C_{\mathrm{cb}}$ trend, whereas in reality, $C_{\text {core }}$ measurements in these anomalous regions actually show fresher pore waters that do not lie on the background trend (Fig. F9). In other words, if the gas hydrate saturation was calculated at the depth of a freshened core sample using the actual measured fresher core salinity rather than the higher core baseline salinity trend by Equation 9 , $S_{\mathrm{h}}$ and $C_{\mathrm{w}}$ would be less. The end result is an overestimation of $S_{\mathrm{h}}$ in areas with higher-than-background gas hydrate saturation, as observed in Figure F8. The method of Hyndman et al. (1999) is limited in areas with heterogeneous gas hydrate distributions because it requires the actual $C_{\text {core }}$ measurement from the same sediment in which the resistivity was measured. However, it does provide a basis for the estimation of an $C_{\mathrm{wb}}$ trend. In areas with background levels of $S_{\mathrm{h}}$ (whether or not they are zero), measurements of $C_{\text {core }}$ lie on the $C_{\mathrm{cb}}$ trend, and the approach provides an accurate estimate of both $S_{\mathrm{h}}$ and $C_{\mathrm{w}}$ because $C_{\mathrm{cb}}$, in this case, is approximately equal to the measured $C_{\text {core }}$. So, although the overall $S_{\mathrm{h}}$ and $C_{\mathrm{w}}$ profiles calculated from the in situ baseline approach have inaccurate zones, their $C_{\mathrm{wb}}$ trends are representative of the true in situ salinity. The $C_{\mathrm{wb}}$ trend can therefore be compared to the $C_{\mathrm{cb}}$ trend to determine if there is regional core freshening from gas hydrate dissociation. At Sites U1325, U1326, and U1329, $C_{\mathrm{wb}}$ is well estimated by $C_{\mathrm{cb}}$ to within the uncertainty of the Archie parameters (Fig. F9) (i.e., taking $C_{\mathrm{cb}}$ as the in situ salinity is a good approximation at these sites). Also, there are many pore water samples showing significant freshening throughout the depth intervals, where the calculated $C_{\mathrm{w}}$ is higher than the core baseline salinity, suggesting that the overestimation is simply the result of using the "wrong" core salinity. However, at Site U1327, $C_{\mathrm{wb}}$ is estimated to be slightly higher than $C_{\mathrm{cb}}$, suggesting a small amount of regional freshening from dissociation upon core recovery may be present. Throughout the depth interval from 150 to 220 mbsf only very little pore water freshening has been seen in the cores; thus, the argument used at Sites U1325 and U1326 does not apply here. The gas hydrate saturation is therefore recalculated at Site U1327 from the core baseline salinity method by using a different estimate of in situ salinity (red line in Fig. F9). This gives slightly higher $S_{\mathrm{h}}$ estimates for this site (Fig. F10). However, as the core hole is a considerable distance from the LWD hole, lateral heterogeneity may be a factor unaccounted for in the above argument, although comparison of the downhole wireline and LWD resistivity logs shows almost identical values around $2 \Omega \mathrm{m}$ for the interval in question (150-220 mbsf).

\section{Uncertainty in porosity}

So far, gas hydrate saturation has been calculated by using the porosity determined from the LWD density log. The same method as described above is applied 
here to neutron porosity and core porosity measurements in order to determine the sensitivity of $S_{\mathrm{h}}$ estimates to the type of porosity measurement.

\section{Neutron porosity}

New Archie parameters need to be calculated for the resistivity versus neutron porosity relation from a cross plot of these measurements in gas hydrate-free zones (Fig. F5B), giving $a=1.74 \pm 0.32$ for $m$ fixed at 1.76. This high value for $a$ further suggests that the neutron porosity log values have a positive bias about the true porosity (possibly related to an incomplete correction for bound water content). Furthermore, the sub-BSR zones used in the Archie parameter estimation could potentially have anomalously high porosity values, caused by the influence of free gas below the BSR on the hydrogen concentration. These zones are kept in the analysis because they significantly add to the range of porosities sampled in the empirical calibration.

In contrast, an unconstrained estimation (no fixed $m$ ) of Archie parameters gives $a=1.41$ and $m=2.09$. However, the $R^{2}$ value of the statistical fit to the data points is only 0.7. The Archie functions for the two sets of empirical parameters predict roughly the same formation factor at the porosity of $\sim 55 \%$. The larger $m$ value of 2.09 introduces significant changes in predicted formation factor and thus gas hydrate concentrations for porosities below $45 \%$ or above $65 \%$. Using an $m$-value of 2.09 instead of 1.76 would result in higher gas hydrate concentrations for porosities above $55 \%$ and lower concentrations for porosities below $55 \%$.

One way to evaluate the total error in predicted gas hydrate concentrations $\left(\Delta S_{\mathrm{h}}\right)$ has been shown by Lee and Collett (2001). For any given $m$-value, $\Delta S_{\mathrm{h}}$ can be written as

$$
\Delta S_{\mathrm{h}}=\frac{\left(1-S_{\mathrm{h}}\right)}{\mathrm{n}} \times\left(\frac{m \Delta \varphi}{\varphi}-\frac{\Delta a}{a}\right) .
$$

Equation 11 shows that $\Delta S_{\mathrm{h}}$ is linearly related to $m$ (i.e., the higher $m$, the higher the total error in the gas hydrate concentration for constant porosity and gas hydrate concentration). It also shows that the error is higher for smaller gas hydrate concentrations at any given porosity and fixed $m$-value. Furthermore, the error in porosity is partially cancelled by the uncertainty in the Archie parameter $a$ itself.

In order to compare the analyses using neutron porosity to those above with density-porosity, we proceed with a fixed $m$-value of 1.76 . Following the protocol outlined above, $C_{\mathrm{w}}$ profiles are calculated from the in situ salinity method at the four sites (Fig. F11). At Sites U1325, U1326, and U1329, $C_{\mathrm{cb}}$ is interpreted to be a good estimate of the true in situ salinity, so the core baseline salinity method is used at these sites to calculate gas hydrate saturation (Fig. F12). At Site U1327, $C_{\mathrm{wb}}$ is again estimated to be slightly higher than $C_{\mathrm{cb}}$; therefore, $C_{\mathrm{wb}}$ (the better estimate of in situ salinity) is used to calculate $S_{\mathrm{h}}$ from the core baseline salinity method. The uncertainty in $a$ accounts for an average uncertainty in $S_{\mathrm{h}}$ of \pm 0.09 . Neutron porosity-based calculations of $S_{\mathrm{h}}$ generally agree with those obtained from the density porosity to within the calculated uncertainty because the bias in porosity is accommodated by the porosity-specific Archie parameters. This highlights the importance of using empirical Archie parameters calibrated to the specific type of measurement made.

As a check, the Archie analysis is repeated for the neutron porosity, using a neutron porosity profile that is shifted so that its mean at each site is equal to the mean density porosity at that site. This approach eliminates some of the biases inherent in the neutron porosity measurement while preserving structure in the log that might not be present in the density porosity profile. This test gives gas hydrate saturation profiles at all sites that are in agreement with both the density porosity-based estimates and the previous estimate from the (nonshifted) neutron porosity to within the uncertainties estimated from the Archie parameters.

The general conclusion from the neutron porosity analysis is that it yields gas hydrate saturation estimates that are similar to those obtained from the density porosity analysis but with larger uncertainties. Gas hydrate saturation estimates using neutron porosity are not particularly sensitive to the bias toward higher porosities present in the neutron log, so long as the Archie parameters are also calibrated to those biased porosity measurements.

\section{Core porosity}

To determine the Archie parameters for the log resistivity versus core porosity data, an average log resistivity value for the $1 \mathrm{~m}$ interval corresponding to the core sample depth was calculated for each core sample in gas hydrate-free zones. The spatial correspondence is only approximate, because the core and log data are from different holes $\sim 50 \mathrm{~m}$ apart. The resistivity versus porosity data are shown in a Pickett plot (Fig. F5C). With $m$ fixed to 1.76 , the best fit to $a$ is $1.43 \pm 0.27$, a value close to that obtained using the density porosity. Note that the statistical uncertainty in $a$ is greater than that for the log density porosity based relation, probably mainly reflecting the fact that the resistivity and core porosity are measured in different holes. Using a best-statistical fit to the data points without any constraints yields $a=1.57$ and $m$ 
$=1.59$ with a very poor $R^{2}$ value of 0.55 . For the same reason of comparison, we proceed again with a fixed $m$-value of 1.76 .

The log resistivity data and core porosity trend are used to calculate $S_{\mathrm{h}}$ following the procedure outlined above. Because core porosity measurements are not available at each log sample, a core porosity trend is calculated at each site (Fig. F2B), as a smoothed profile (a least-squares fit) through the core porosity data, using Athy's law, emulating compaction and porosity loss with depth (Athy, 1930):

$$
\varphi(z)=\varphi_{0} e^{-z / L},
$$

where $z$ is the depth below seafloor, $\varphi_{0}$ is the porosity at the seafloor, and $L$ is a characteristic decay constant. Equation 9 is then used to calculate the $C_{\mathrm{w}}$ profile from which the $C_{\mathrm{wb}}$ trend is estimated. $C_{\mathrm{wb}}$ is compared to the $C_{\mathrm{cb}}$ trend to assess whether or not $C_{\mathrm{cb}}$ is a good estimate of the true in situ salinity (Fig. F13). $C_{w b}$ profiles calculated for Sites U1326 and U1327 give trends with slightly greater in situ salinity than $C_{\mathrm{cb}} . S_{\mathrm{h}}$ is then calculated from the core baseline salinity method, using $C_{\mathrm{wb}}$ at Sites U1326 and U1327 and $C_{\mathrm{cb}}$ at Sites U1325 and U1329 (Fig. F14). Uncertainties in Archie parameters account for an average uncertainty in $S_{\mathrm{h}}$ of \pm 0.08 .

Gas hydrate saturation calculated from core porosity and $\log$ density porosity are generally in good agreement because $S_{\mathrm{h}}$ profiles calculated from these two porosity measurements have uncertainty bounds that overlap in most areas (Fig. F14). One exception is at Site U1327, where $S_{\mathrm{h}}$ calculated from the core porosity is on average 0.09 greater in the interval of accreted sediments above the BSR (90-225 mbsf). The difference at this site occurs because the porosity profile observed in the log is not well represented by the smoothed Athy-type porosity-depth relation applied to the core data. Although there is no significant overall bias between the log density porosity and the core porosity trend, there are local biases at certain depths (Fig. F2B). In the accreted section above the BSR (90-225 mbsf), with the exception of the high-porosity unit at 120-138 mbsf, the log density porosity is almost exclusively lower than the core porosity trend. Because the Archie parameters (calculated for an average porosity-resistivity relation) are similar for the core and log density porosity, $S_{\mathrm{h}}$ and $C_{\mathrm{w}}$ are biased toward higher values in this interval because of the local porosity bias.

Although the results from the core porosity analysis are reasonable, gas hydrate saturation estimates based on log density porosity measurements are preferred for the following reasons. Core porosities are disadvantaged because (1) they need to use a trend that is smoothed over depth to match the sampling of the resistivity log; (2) they have been measured in samples from different holes than the resistivity data, leading to additional uncertainty caused by interhole variability; and (3) the porosity is measured onboard the ship, after core recovery, rather than in situ.

The log density porosities have the disadvantage that porosity is not measured directly. Porosity is estimated from log density, assuming first that the formation bulk density is well related to the measured electron density and second that the average grain density used in an adequate approximation.

\section{Summary and discussion}

The goal of this study was to estimate gas hydrate saturation from the electrical logs and porosity estimators using Archie analysis while addressing uncertainties in (1) Archie parameters, (2) in situ salinity, and (3) in situ porosity. In this study, estimates of in situ salinity were obtained as accurately as possible and gas hydrate saturation estimates were reported with uncertainties related primarily to Archie parameter estimation. The analysis of the different available porosity measurements showed that a bias in porosity does not significantly affect the gas hydrate saturation estimate so long as the Archie parameters have been properly estimated. However, the most reliable porosity measurement was concluded to be the log density porosity because it is well calibrated to the core porosities and was measured in the same hole as was the resistivity. Uncertainties in the density porosity measurement arise mainly from the statistical uncertainty in the gamma ray count used to calculate the density and the error induced by using an average grain density in mapping bulk density to porosity. However, assuming that these sources of error produce random unbiased noise in the data, they are inherently included in the Archie parameter uncertainties and have therefore been accounted for.

Considering the estimates from density porosity to be the most accurate, gas hydrate saturations averaged over a $10 \mathrm{~m}$ window (Fig. F10) show distributed gas hydrate occurrence in many intervals $\left(S_{\mathrm{h}}=\sim 0.09\right.$ \pm 0.07 at Site U1326 [170-200 mbsf]; $S_{\mathrm{h}}=\sim 0.10 \pm$ 0.07 at Site U1325 [190-230 mbsf]; $S_{\mathrm{h}}=\sim 0.11 \pm 0.07$ at Site U1327 [140-225 mbsf]), with average concentrations of $5 \%-15 \%$ of the pore space, over depth intervals of $20-100 \mathrm{~m}$. However, despite the inter- 
preted distributed gas hydrate occurrences, the general agreement between $C_{\mathrm{cb}}$ and $C_{\mathrm{wb}}$ indicate that core salinity measurements can sample pore water that has not been freshened by gas hydrate dissociation upon core recovery. This finding suggests that, on the scale of individual log or core measurements, it is possible to sample gas hydrate-free zones, but at the meter scale, gas hydrate occurrence appears distributed.

One possible exception is at Site U1327, where general core salinity is much lower than seawater. It is concluded that most of the low core salinity is due to a source of low salinity fluid, probably from deeper in the section. However, the estimated $C_{w b}$ is slightly higher than $C_{\mathrm{cb}}$, suggesting a minor amount of regional freshening of core salinities from gas hydrate dissociation of pervasive gas hydrate upon core recovery. $C_{\mathrm{wb}}$ is greater than $C_{\mathrm{cb}}$ by $\sim 1.5 \%$, corresponding to a background gas hydrate pore space saturation of $\sim 3 \%$, but the uncertainties are large. Based on the estimate of $C_{\mathrm{wb}}$ at the BSR, the difference between the background freshening measured in core ( $22 \%$ o salinity) and seawater (35\% salinity) is attributed mostly to regional freshening from deeper sources of freshwater, with $\sim 10 \%$ from pervasive gas hydrate freshening. A final answer to this question can only be obtained from direct pore water sampling in situ, which is proposed through Osmo-sampling as part of the second phase of Expedition 311.

Additionally, intervals of very high gas hydrate saturation of $>40 \%$ of the pore space are observed at Sites U1326 (73-94 mbsf) and U1327 (120-138 mbsf) and were interpreted to be high-porosity sandy turbidite units in which large amounts of gas hydrate has formed. The correlation between these coarsergrained turbidite units and high gas hydrate saturation is the principal observation supporting the hypothesis that gas hydrate occurrence is largely controlled by sediment grain size and associated formation parameters, such as permeability (see the "Expedition 311 summary" chapter).

\section{Comparison with previous interpretation}

The gas hydrate saturation estimates from this more comprehensive study at Site U1327 differ significantly from the previous downhole resistivity study at nearby Site 889 of Hyndman et al. (1999). They estimated $25 \%-30 \%$ gas hydrate pore space saturation in the $100 \mathrm{~m}$ interval above the BSR, compared to the $5 \%-15 \%$ estimated in this study. This discrepancy is mainly attributed to the choice of pore water salinity baseline used in the analysis, the porosity measurement, and associated formulation of Archie's equation used to estimate gas hydrate saturations.

Hyndman et al. (1999) used a smoothed fit to core porosities in their analysis, whereas here the best results are taken to be those obtained from the log density porosity. In this analysis, using a smoothed core porosity trend yielded $15 \%-25 \%$ gas hydrate pore space saturation in the $100 \mathrm{~m}$ interval above the BSR at Site U1327. The difference is that in the $100 \mathrm{~m}$ above the BSR, the core porosity is (locally) biased relative to the log density porosity. Because the resistivity is the same, the porosity bias must, to first order, be compensated for by an equivalent volume of gas hydrate (because the Archie parameters are very similar), resulting in higher gas hydrate saturation estimates.

The second reason for the discrepancy is that Hyndman et al. (1999) estimated $S_{\mathrm{h}}$ directly from the in situ salinity method, whereas in this study $C_{w b}$ is estimated from the in situ salinity method and used as the salinity profile in the core baseline salinity method to calculate $S_{\mathrm{h}}$. The in situ salinity method, used on its own, overestimates $S_{\mathrm{h}}$ in areas where core salinities are freshened relative to $C_{\mathrm{cb}}$. This occurs because the in situ salinity method is only truly accurate if the resistivity and core salinity are measured on the same physical sample. This difference accounts for a difference in $S_{\mathrm{h}}$ of $0-0.08$ in the $100 \mathrm{~m}$ interval above the BSR.

Finally, a minor contribution to the difference in the results is that the simplification $n=m$ adopted in the Archie analysis of Hyndman et al. (1999) accounts for an increase in gas hydrate saturation of $\sim 4 \%$ (Riedel et al., 2005). All these factors combined account for a difference of $14 \%-22 \%$ gas hydrate saturation, which is approximately the difference between the reported estimates at Sites U1327 and 889.

\section{Acknowledgments}

Samples and/or data were provided by the Integrated Ocean Drilling Program (IODP). We would like to thank IODP, the National Science Foundation, and the U.S. Department of Energy National Gas Hydrate Research Program for making this research possible. We also acknowledge the contribution of the shipboard scientific party of Expedition 311. Funding was provided by the Geological Survey of Canada and the National Sciences and Engineering Research Council of Canada. This paper is Geological Survey of Canada Contribution No. 20080111. We also acknowledge the constructive external reviewer for useful comments. 


\section{References}

Archie, G.E., 1942. The electrical resistivity $\log$ as an aid in determining some reservoir characteristics. Trans. Am. Inst. Min., Metall. Pet. Eng., 146:54-62.

Athy, L.F., 1930. Density, porosity, and compaction of sedimentary rocks. AAPG Bull., 14:1-24.

Blum, P., 1997. Physical properties handbook: a guide to the shipboard measurement of physical properties of deep-sea cores. ODP Tech. Note, 26. doi:10.2973/ odp.tn.26.1997

Collett, T.S., 2001. A review of well-log analysis techniques used to assess gas-hydrate-bearing reservoirs. In Paull, C.K., and Dillon, W.P. (Eds.), Natural Gas Hydrates: Occurrence, Distribution, and Detection. Geophys. Monogr., 124:189-210.

Collett, T.S., and Ladd, J., 2000. Detection of gas hydrate with downhole logs and assessment of gas hydrate concentrations (saturations) and gas volumes on the Blake Ridge with electrical resistivity log data. In Paull, C.K., Matsumoto, R., Wallace, P.J., and Dillon, W.P. (Eds.), Proc. ODP, Sci. Results, 164: College Station, TX (Ocean Drilling Program), 179-191. doi:10.2973/ odp.proc.sr.164.219.2000

Fofonoff, N.P., 1985. Physical properties of seawater: a new salinity scale and equation of state for seawater. J. Geophys. Res., 90(C2):3332-3342. doi:10.1029/ JC090iC02p03332

Goldberg, D., Wilkens, R.H., and Moos, D., 1987. Seismic modeling of diagenetic effects in Cenozoic marine sediments at Deep Sea Drilling Project Sites 612 and 613. In Poag, C.W., Watts, A.B., et al., Init. Repts. DSDP, 95: Washington, DC (U.S. Govt. Printing Office), 589-599. doi:10.2973/dsdp.proc.95.123.1987

Hamilton, E.L., 1976. Variations of density and porosity with depth in deep-sea sediments. J. Sediment. Petrol., 46:280-300.

Hearst, J.R., Nelson, P.H., and Paillet, F.L., 2000. Well Logging for Physical Properties: A Handbook for Geophysicists, Geologists, and Engineers (2nd ed.): New York (J. Wiley and Son).

Hesse, R., 2003. Pore water anomalies of submarine gashydrate zones as tool to assess hydrate abundance and distribution in the subsurface-what have we learned in the past decade? Earth-Sci. Rev., 61(1-2):149-179. doi:10.1016/S0012-8252(02)00117-4

Hilfer, R., 1991. Geometric and dielectric characterization of porous media. Phys. Rev., 44(1):60-75. doi:10.1103/ PhysRevB.44.60

Hyndman, R.D., Yuan, T., and Moran, K., 1999. The concentration of deep sea gas hydrates from downhole electrical resistivity logs and laboratory data. Earth Planet. Sci. Lett., 172(1-2):167-177. doi:10.1016/S0012821X(99)00192-2

Ioannidis, M.A., Kwiecien, M.J., and Chatzis, I., 1997. Electrical conductivity and percolation aspects of statistically homogeneous porous media. Transp. Porous Media, 29(1):61-83. doi:10.1023/A:1006557614527
Jackson, P.D., Taylor Smith, D., and Stanford, P.N., 1978. Resistivity-porosity-particle shape relationships for marine sands. Geophysics, 43(6):1250-1268. doi:10.1190/1.1440891

Kastner, M., Kvenvolden, K.A., Whiticar, M.J., Camerlenghi, A., and Lorenson, T.D., 1995. Relation between pore fluid chemistry and gas hydrates associated with bottom-simulating reflectors at the Cascadia margin, Sites 889 and 892. In Carson, B., Westbrook, G.K., Musgrave, R.J., and Suess, E. (Eds.), Proc. ODP, Sci. Results, 146 (Pt. 1): College Station, TX (Ocean Drilling Program), 175-187. doi:10.2973/odp.proc.sr.1461.213.1995

Kvenvolden, K.A., 1993. Gas hydrates-geological perspective and global change. Rev. Geophys., 31(2):173-187. doi:10.1029/93RG00268

Lee, M.W., and Collett, T.S., 2001. Gas hydrate estimation error associated with uncertainties of measurements and parameters. U.S. Geol. Surv. Bull., 2182. http://geology.cr.usgs.gov/pub/bulletins/b2182/

Pearson, C.F., Halleck, P.M., McGuire, P.L., Hermes, R., and Mathews, M., 1983. Natural gas hydrate deposits: a review of in situ properties. J. Phys. Chem., 87(21):41804185. doi:10.1021/j100244a041

Riedel, M., Collett, T.S., and Hyndman, R.D., 2005. Gas hydrate concentration estimates from chlorinity, electrical resistivity, and seismic velocity. Geol. Surv. Can. Open-File Rep., 4934.

Riedel, M., Collett, T.S., Malone, M.J., and the Expedition 311 Scientists, 2006. Proc. IODP, 311: Washington, DC (Integrated Ocean Drilling Program Management International, Inc.). doi:10.2204/iodp.proc.311.2006

Sloan, E.D., 1998. Clathrate Hydrates of Natural Gases (2nd ed.): New York (Marcel Dekker).

Spangenberg, E., 2001. Modeling of the influence of gas hydrate content on the electrical properties of porous sediments. J. Geophys. Res.,106(B4):6535-6548. doi:10.1029/2000JB900434

Swanson, B.F., 1979. Visualizing pores and nonwetting phase in porous rock. JPT, J. Pet. Technol., 31(1):10-18. doi:10.2118/6857-PA

Westbrook, G.K., Carson, B., Musgrave, R.J., et al., 1994. Proc. ODP, Init. Repts., 146 (Pt. 1): College Station, TX (Ocean Drilling Program). doi:10.2973/ odp.proc.ir.146-1.1994

Winsauer, W.O., and Shearin, H.M., Jr., 1952. Resistivity of brine-saturated sands in relation to pore geometry. AAPG Bull., 36:253-277. doi:10.1306/3D9343F4-16B111D7-8645000102C1865D

Winters, W.J., 2000. Data report: effects of drying methods and temperatures on water content and porosity of sediment from the Blake Ridge. In Paull, C.K., Matsumoto, R., Wallace, P.J., and Dillon, W.P. (Eds.), Proc. ODP, Sci. Results, 164: College Station, TX (Ocean Drilling Program), 431-434. doi:10.2973/ odp.proc.sr.164.240.2000 
Yuan, J., and Edwards, R.N., 2000. The assessment of marine gas hydrates through electrical remote sounding: hydrate without a BSR? Geophys. Res. Lett., 27(16):2397-2400. doi:10.1029/2000GL011585

Yuan, T., Hyndman, R.D., Spence, G.D., and Desmons, B., 1996. Seismic velocity increase and deep-sea gas hydrate concentration above a bottom-simulating reflector on the northern Cascadia Continental Slope. J. Geophys. Res., 101(B6):13655-13671. doi:10.1029/96JB00102

Initial receipt: 3 May 2008

Acceptance: 30 July 2008

Publication: 21 November 2008

MS 311-203 
Figure F1. A. Bathymetry map of the northern Cascadia accretionary prism with Expedition 311 sites and multichannel seismic (MCS) Line 89-08 through the well transect. B. Seismic cross section of the northern Cascadia accretionary prism (Line 89-08). BSR = bottom-simulating reflector.
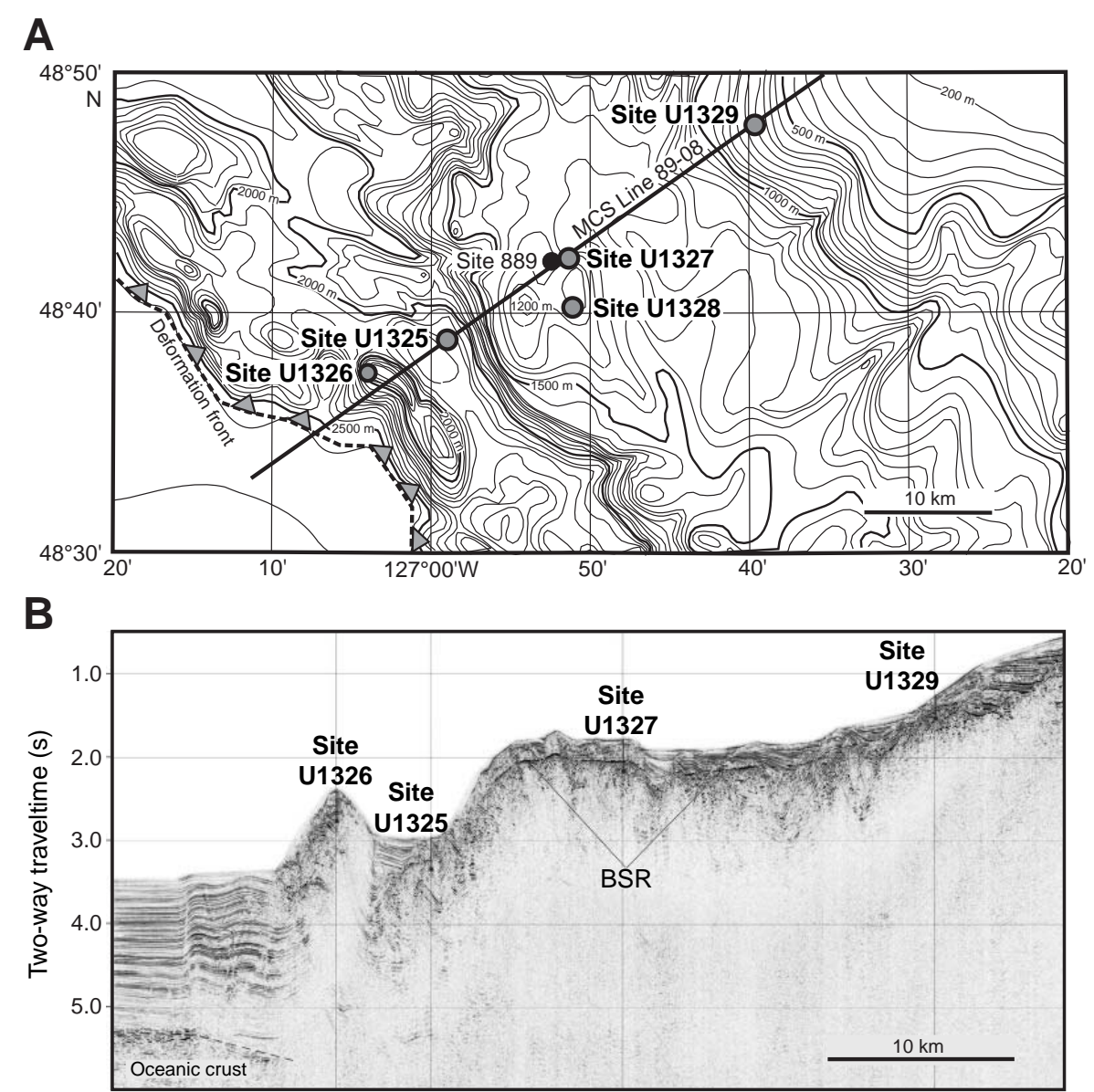
Figure F2. Downhole LWD measurements. A. Resistivity logs. Solid line = seismically inferred bottom-simulating reflector (BSR). B. Porosity. Zones with poor log quality have been removed.
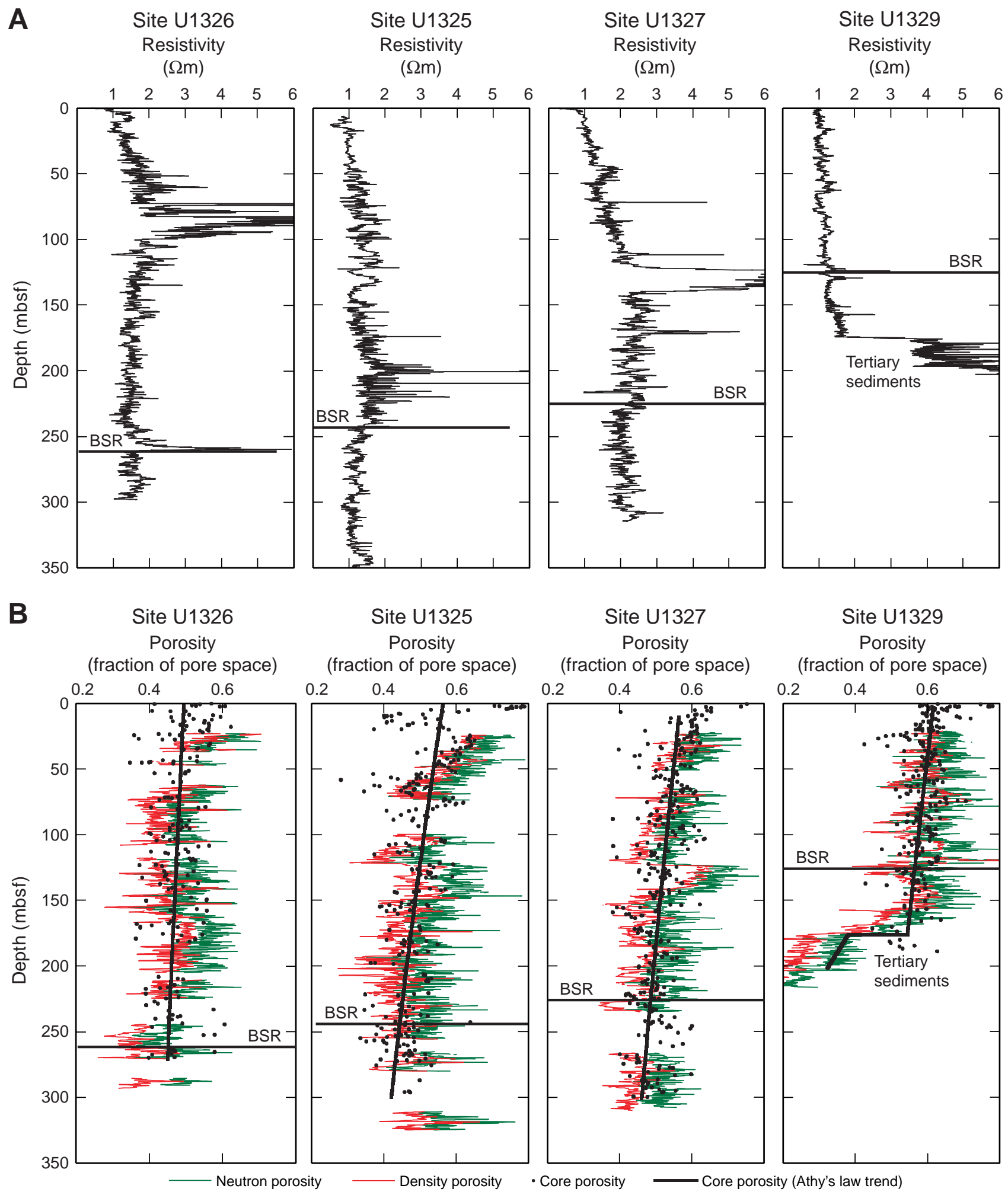
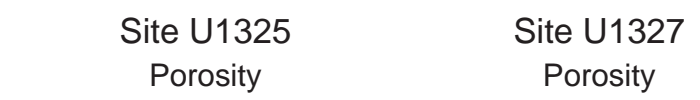

(fraction of pore space) (fraction of pore space)

\section{Site U1329 \\ Porosity} $\begin{array}{llll}0.2 & 0.4 & 0.6 & 0.2\end{array}$
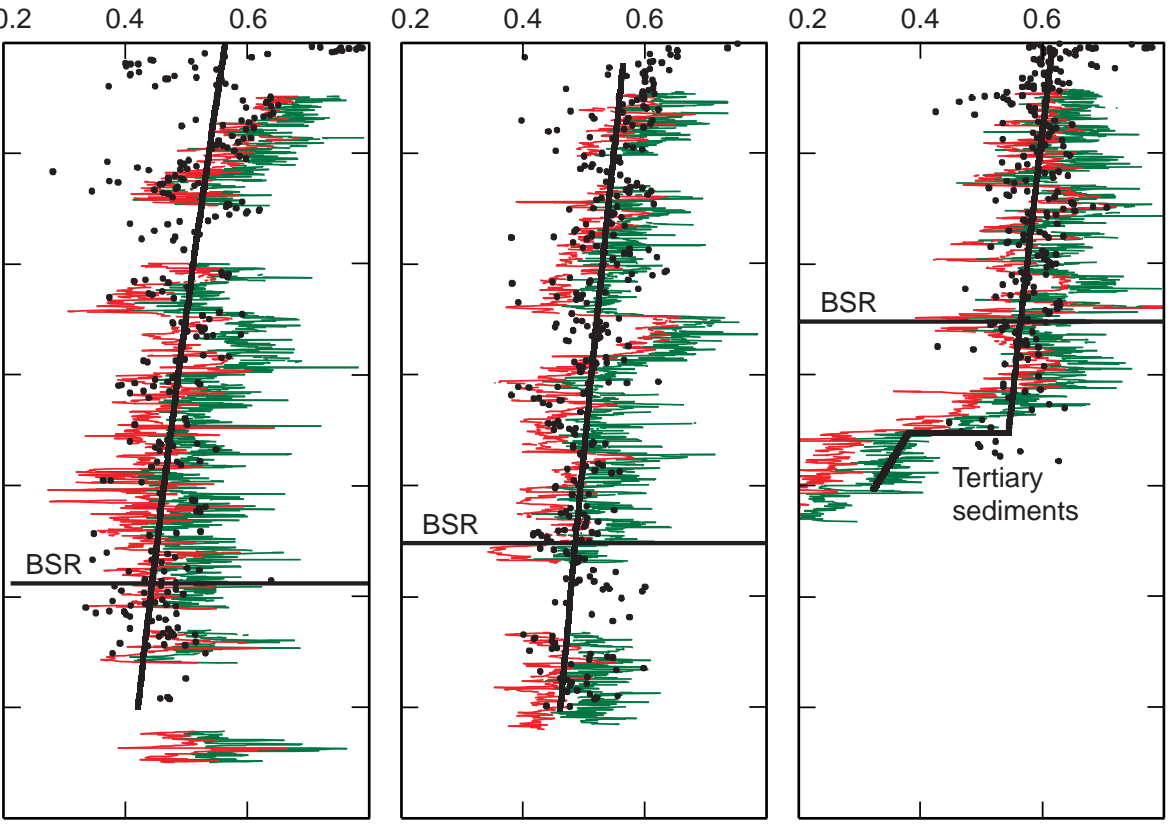
Figure F3. Compilation of log resistivity data. Wireline resistivity logs were recorded in Holes 889A, 889B, and U1327E, whereas Hole U1327A was recorded by LWD. With the exception of Hole U1327A, measured resistivities are similar between holes. BSR = bottom-simulating reflector.
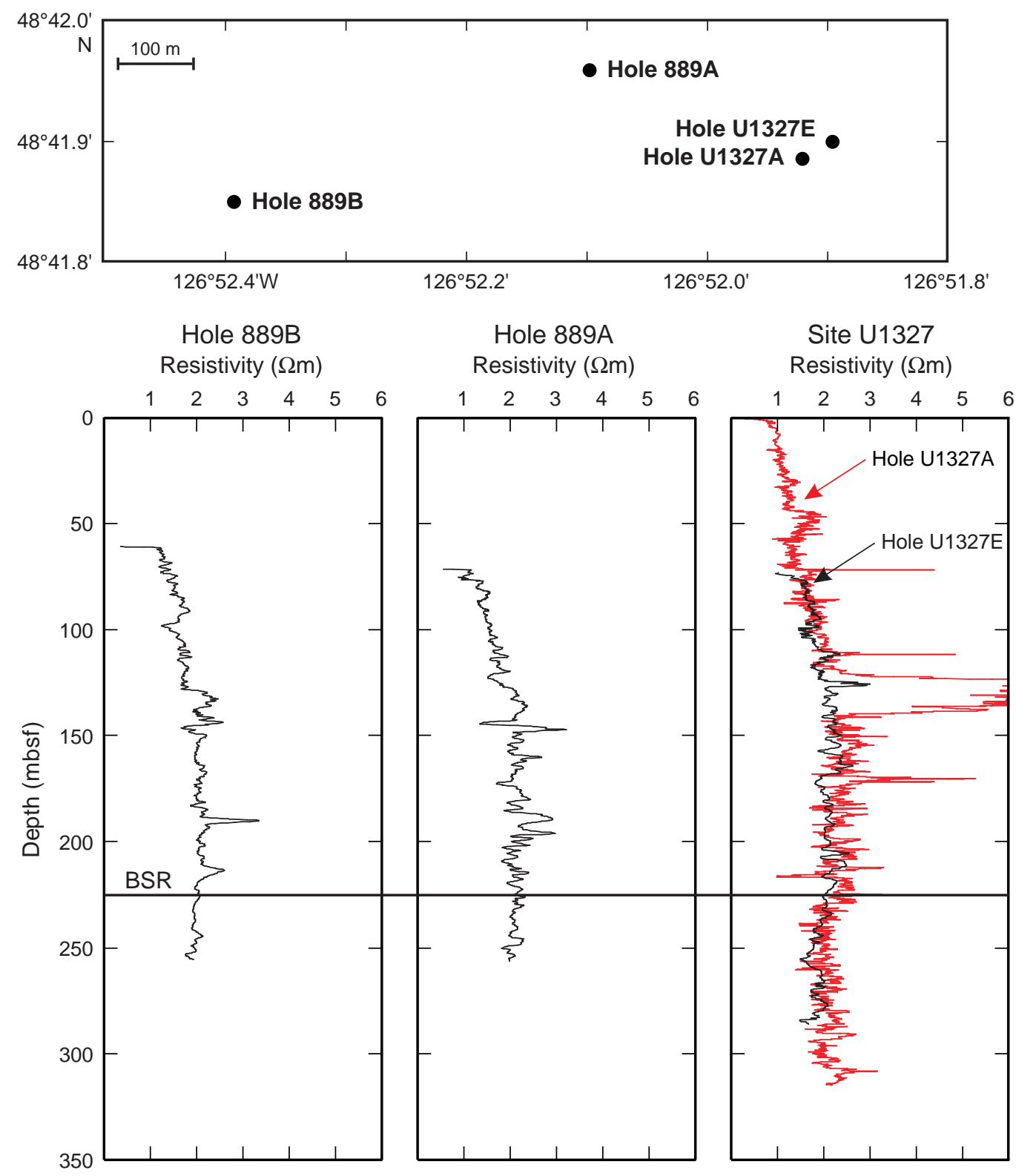
Figure F4. Core salinity measurements. Solid line = estimated core salinity baseline. BSR = bottom-simulating reflector.

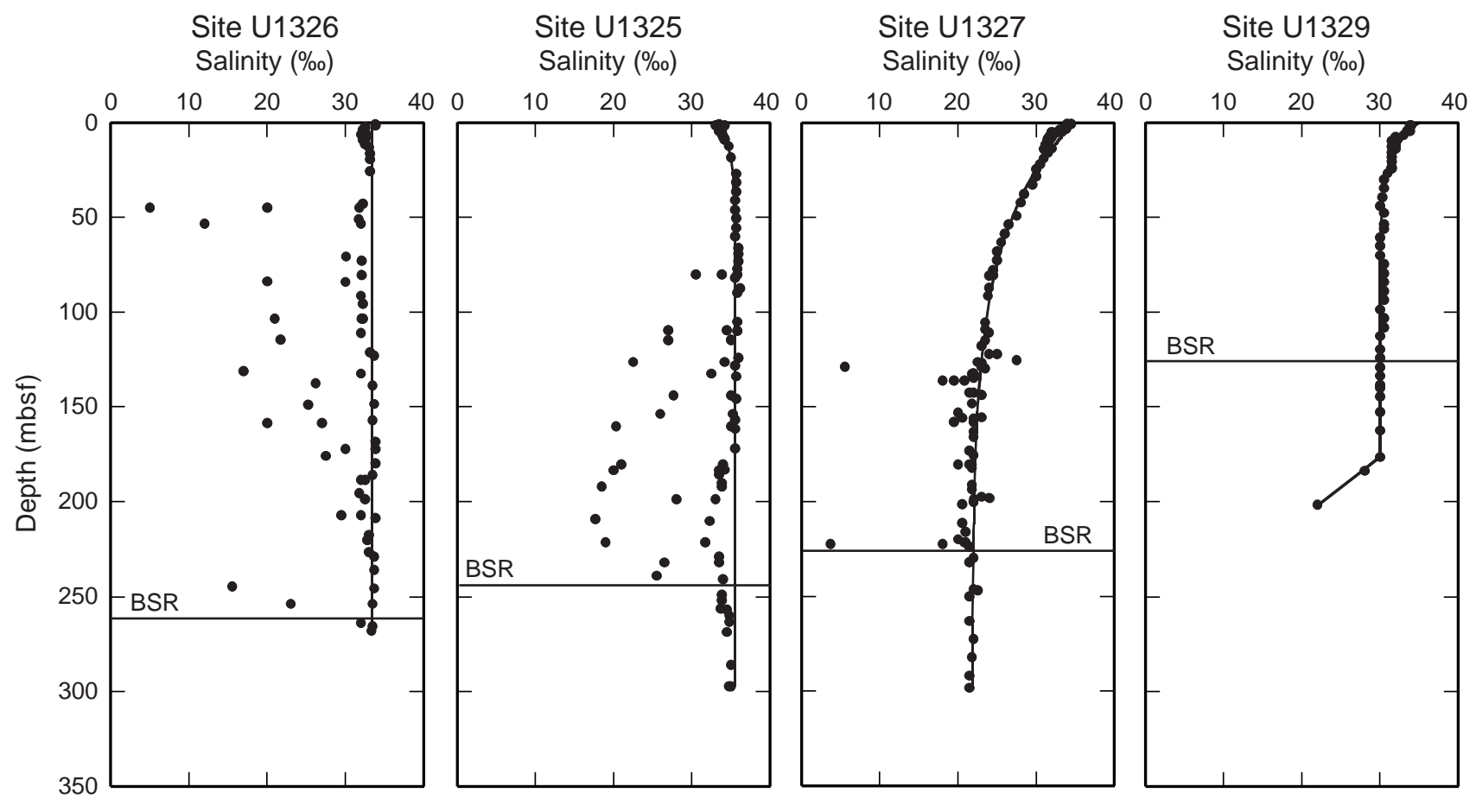


Figure F5. Formation factor vs. porosity (Pickett plot) for no-hydrate intervals of the well transect. Data points are taken from no-hydrate slope basin sediments and subbottom-simulating reflector (sub-BSR) zones. In all analyses, $m$ was fixed to 1.76. A. Using density porosity yields $a=1.38$ \pm 0.18 . B. Using neutron porosity yields $a=1.74 \pm 0.32$. C. Using core porosity yields $a=1.43 \pm 0.27$. For comparison, Hyndman et al. (1999) and Collett (2001) calculated Archie parameters of $a=1.41, m=1.76$, and $a=0.97, m=2.81$. s.d err. $=$ standard deviation error.

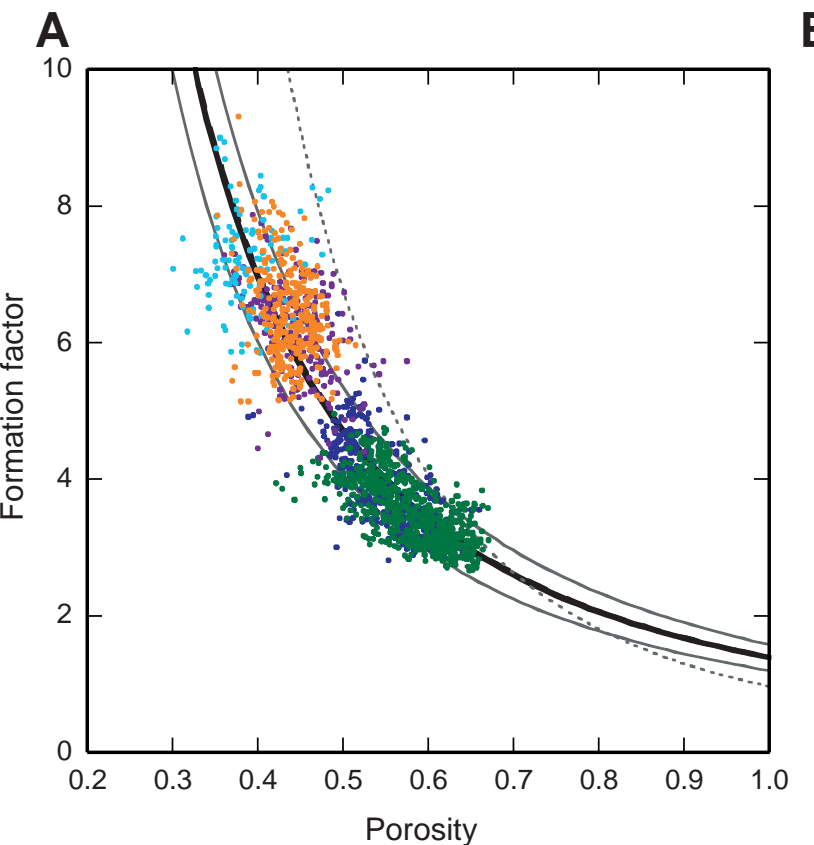

- Site U1327 slope basin - Site U1325 sub-BSR - Site U1329 slope basin . Site U1326 sub-BSR
B

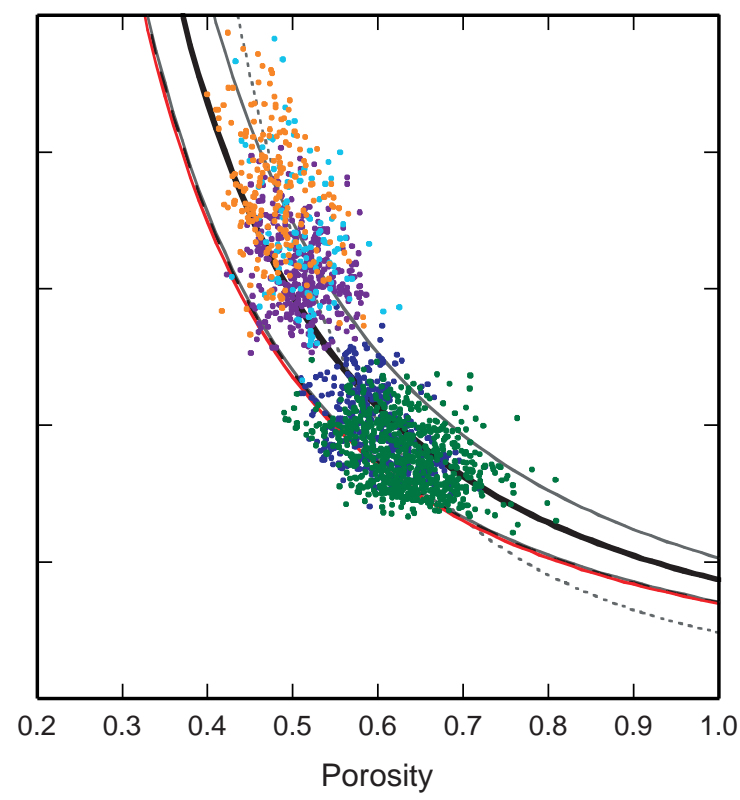

- Site U1327 sub-BSR

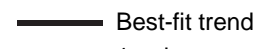
1 s.d. err.
C

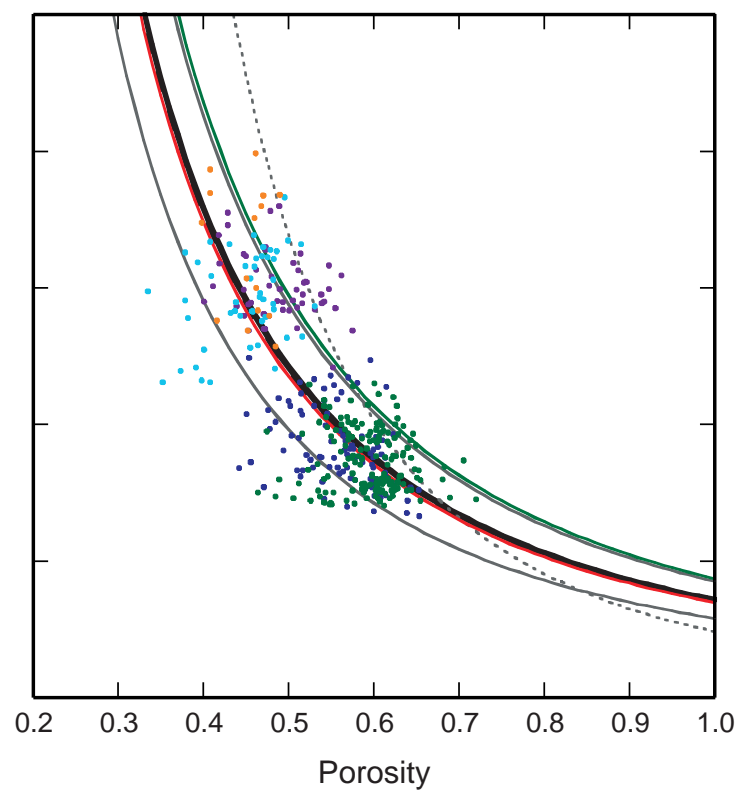

Density porosity Neutron porosity 
Figure F6. Measured LWD resistivity $\left(R_{\mathrm{t}}\right)$ and 100\% water-saturated resistivity $\left(R_{\mathrm{o}}\right)$ determined from Archie analysis of downhole data. $R_{\mathrm{o}}$ is calculated from log density porosity and core baseline salinity. BSR = bottomsimulating reflector.

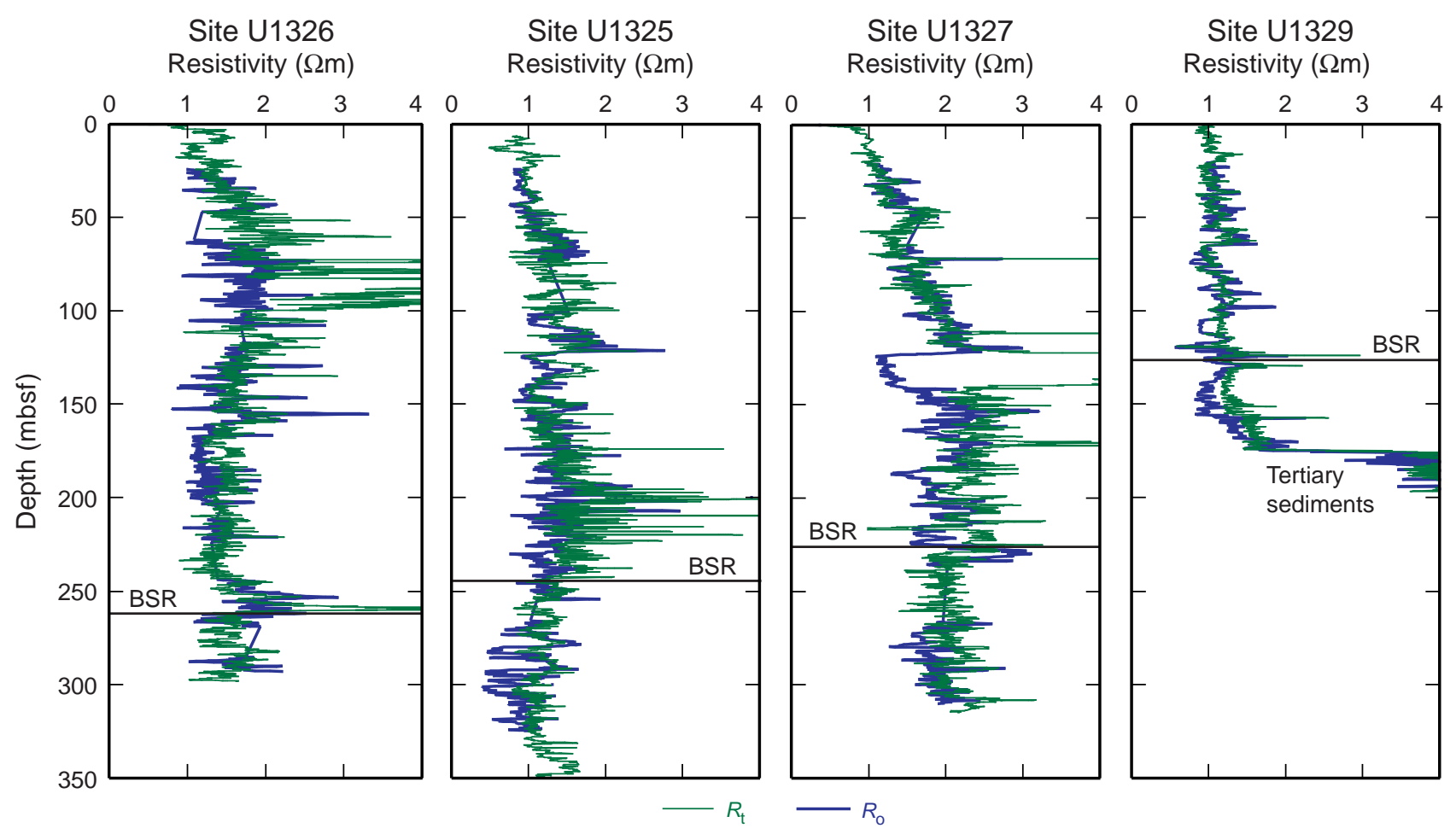


Figure F7. Gas hydrate saturation estimates calculated using log density porosity and core baseline salinity method. Gray lines $=1 \sigma$ error from uncertainty in Archie parameter estimation. BSR = bottom-simulating reflector.

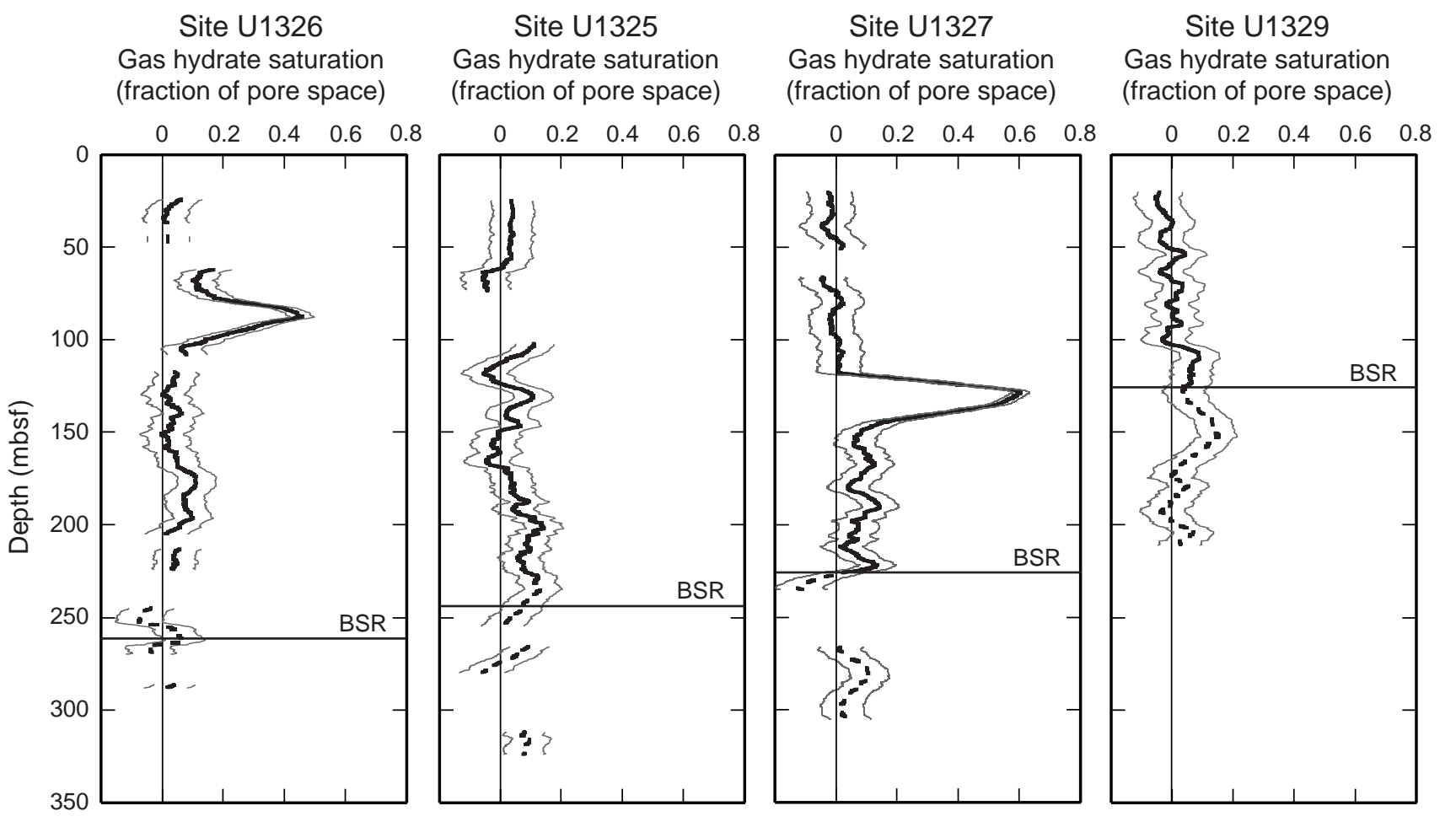


Figure F8. Gas hydrate saturation estimates calculated using log density porosity and in situ salinity method (black lines). Gray $=1 \sigma$ from uncertainty in Archie parameter estimation, blue $=$ saturation estimate from core baseline salinity method. BSR = bottom-simulating reflector.

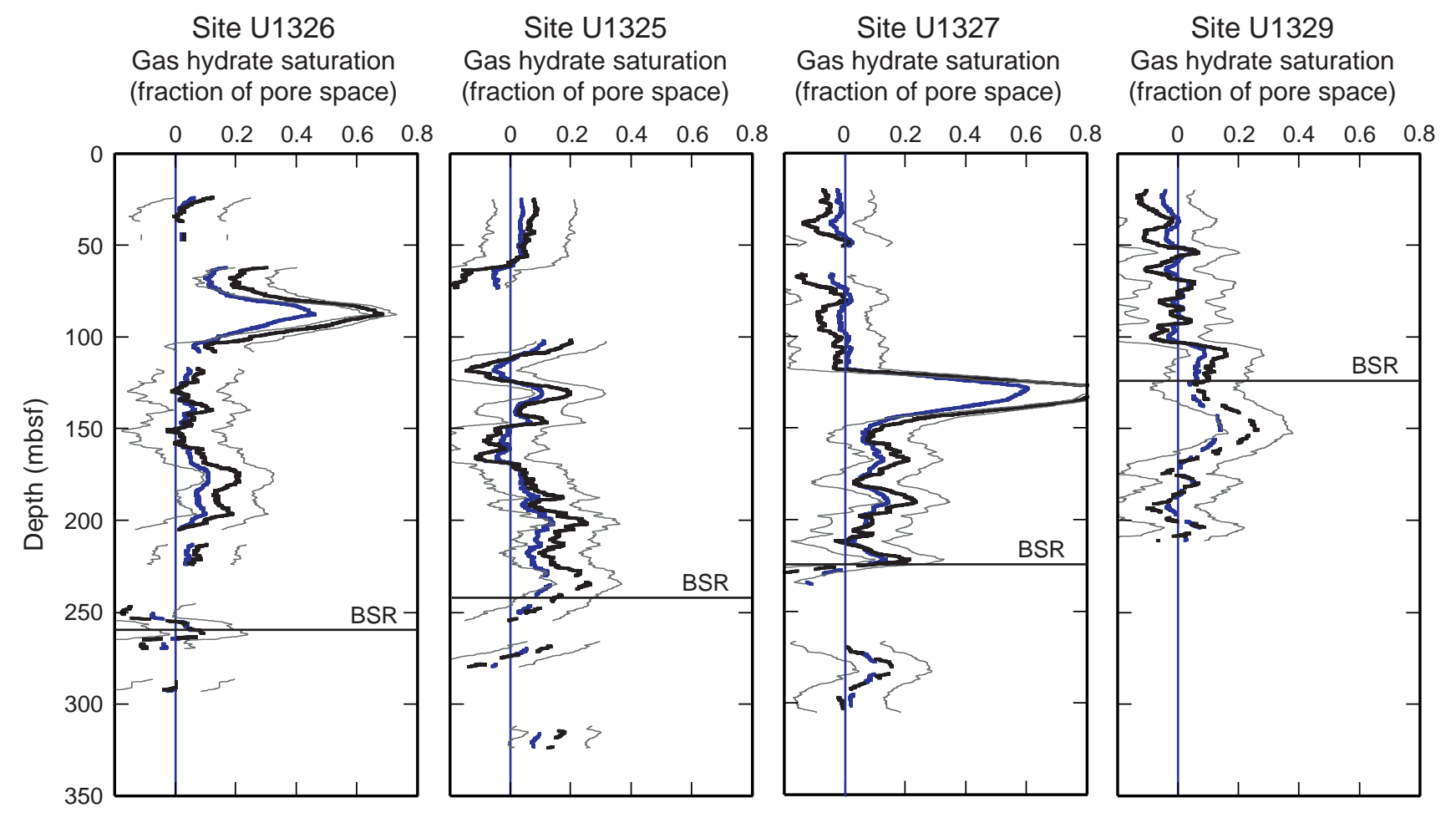


Figure F9. In situ pore water salinity concentration calculated from in situ salinity method, based on log density porosity. Green = calculated in situ salinity, gray $=1 \sigma$ error from the uncertainty in Archie parameter estimation, blue dots $=$ core salinity measurements, blue line $=$ core baseline salinity trend, red $=$ reestimated in situ baseline salinity trend. BSR = bottom-simulating reflector.

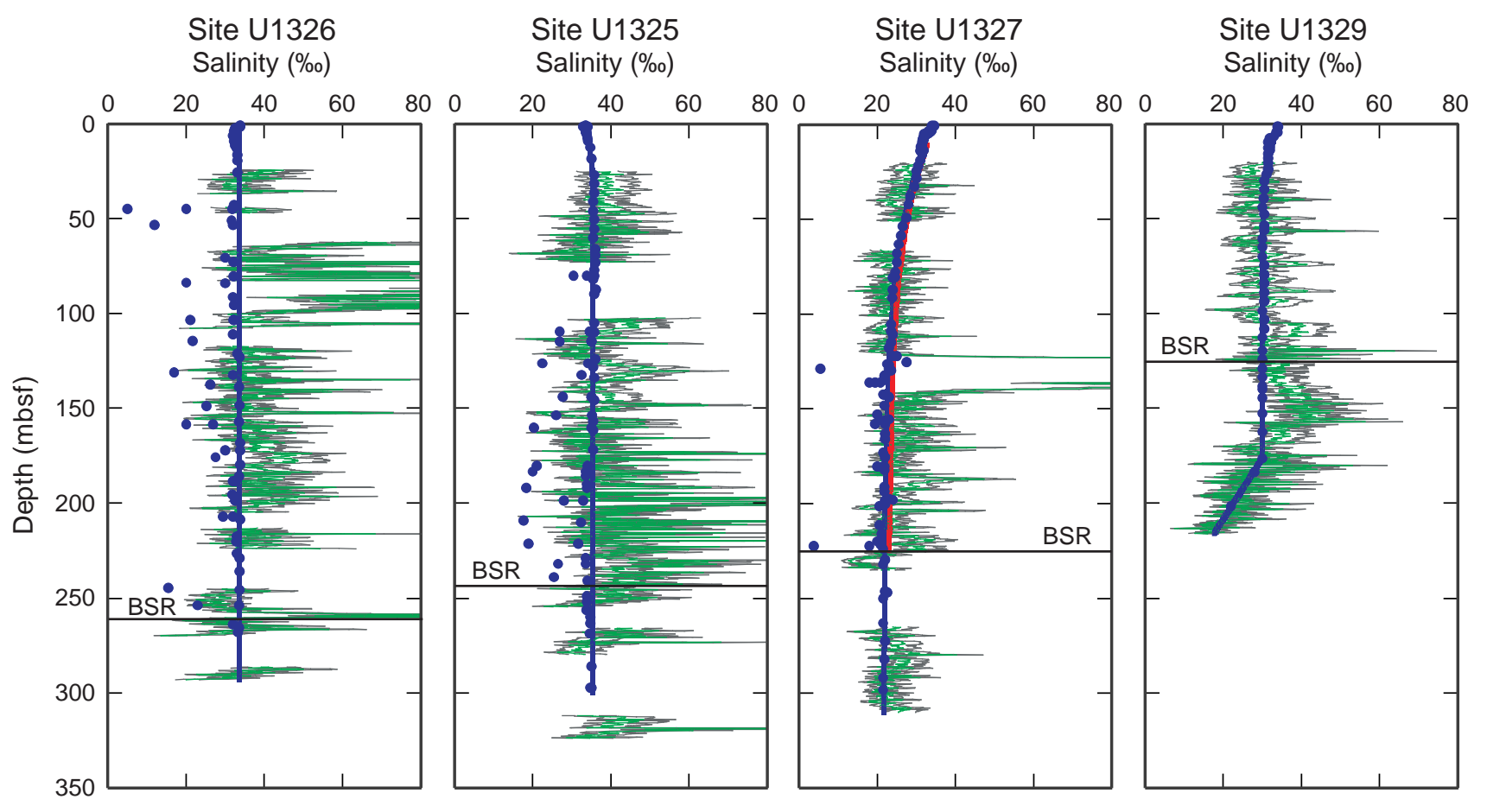


Figure F10. Gas hydrate saturation estimates calculated using log density porosity and baseline salinity method (black lines), with new baseline salinity profile for Site U1327. Gray $=1 \sigma$ error from uncertainty in Archie parameter estimation, blue = estimate from core baseline salinity. BSR = bottom-simulating reflector.

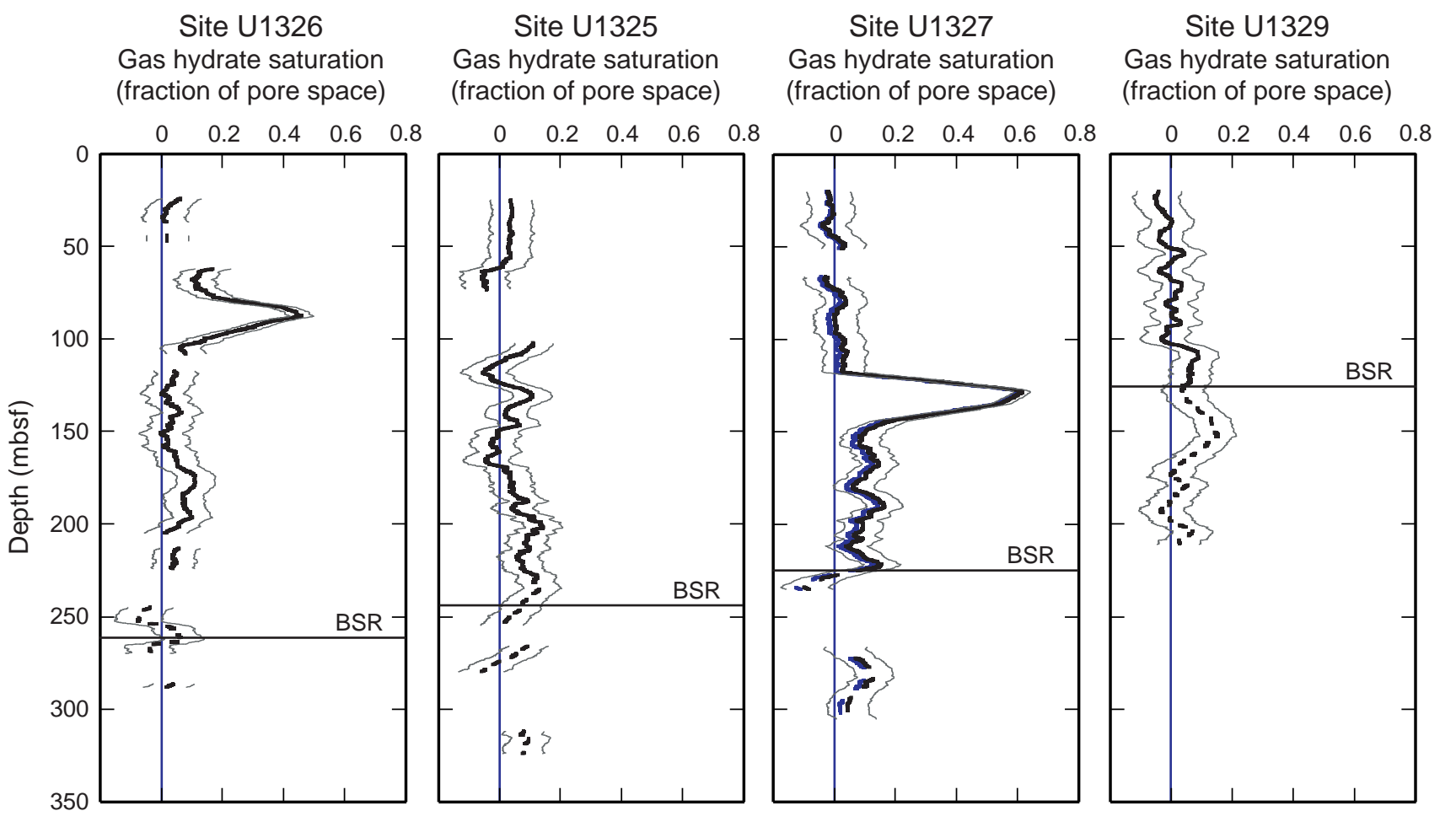


Figure F11. In situ pore water salinity concentration calculated from in situ salinity method, based on log neutron porosity. Green $=$ calculated in situ salinity, gray $=1 \sigma$ error from the uncertainty in Archie parameter estimation, blue dots $=$ core salinity measurements, blue line $=$ core baseline salinity trend, red $=$ reestimated in situ baseline salinity trend. BSR = bottom-simulating reflector.

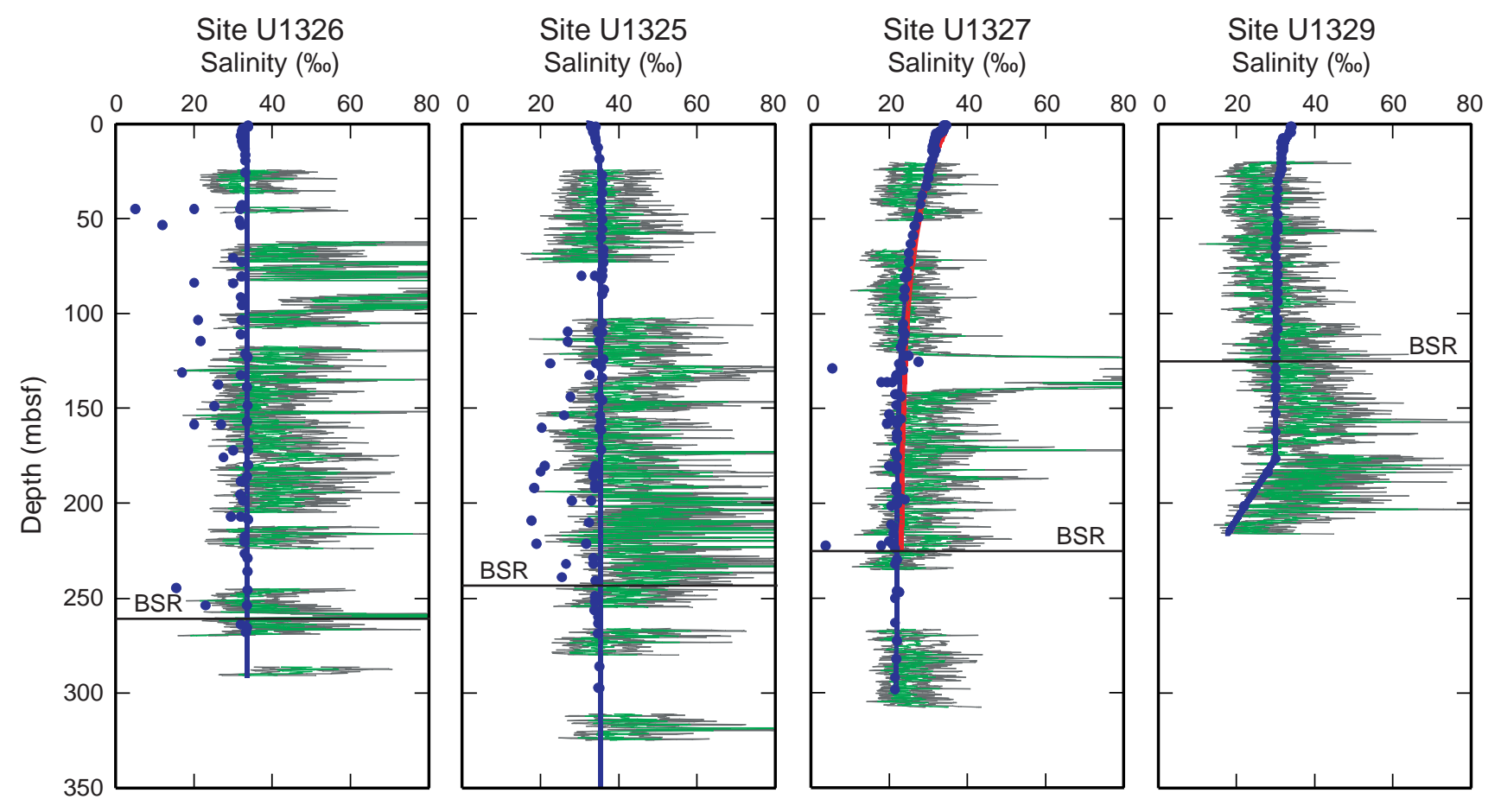


Figure F12. Gas hydrate saturation estimates calculated using the log neutron porosity and the baseline salinity method (black lines), with new baseline salinity profile for Site U1327. Gray $=1 \sigma$ error from the uncertainty in Archie parameter estimation, blue = density porosity based estimates. BSR = bottom-simulating reflector.

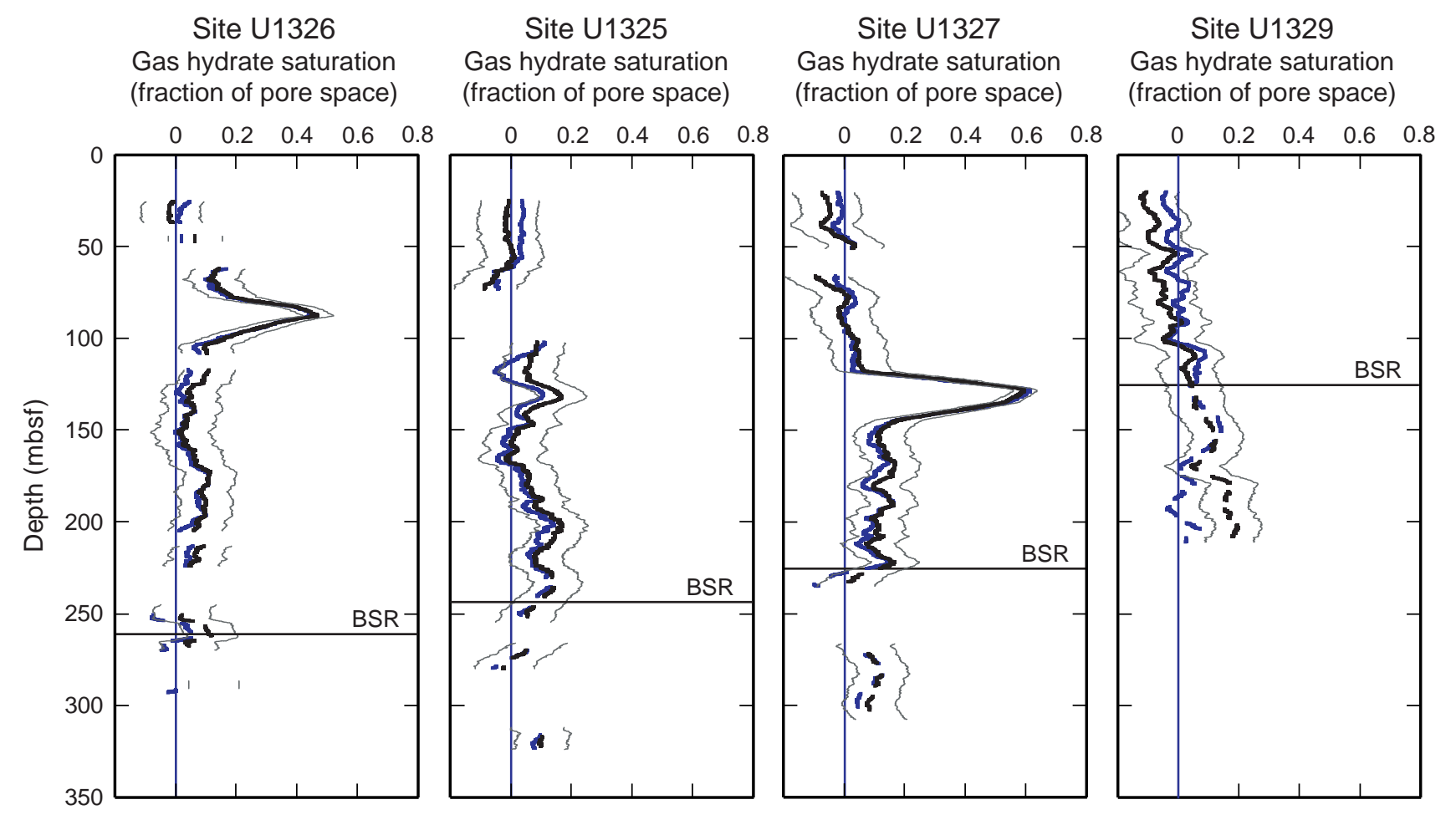


Figure F13. In situ pore water salinity concentration calculated from in situ salinity method, based on core porosities. Green $=$ calculated in situ salinity, gray $=1 \sigma$ error from the uncertainty in Archie parameter estimation, blue dots $=$ core salinity measurements, blue $=$ core baseline salinity trend, red $=$ reestimated in situ baseline salinity trend. At Sites U1325 and U1329, core baseline salinity is a good estimate of in situ baseline salinity. $\mathrm{BSR}=$ bottom-simulating reflector.

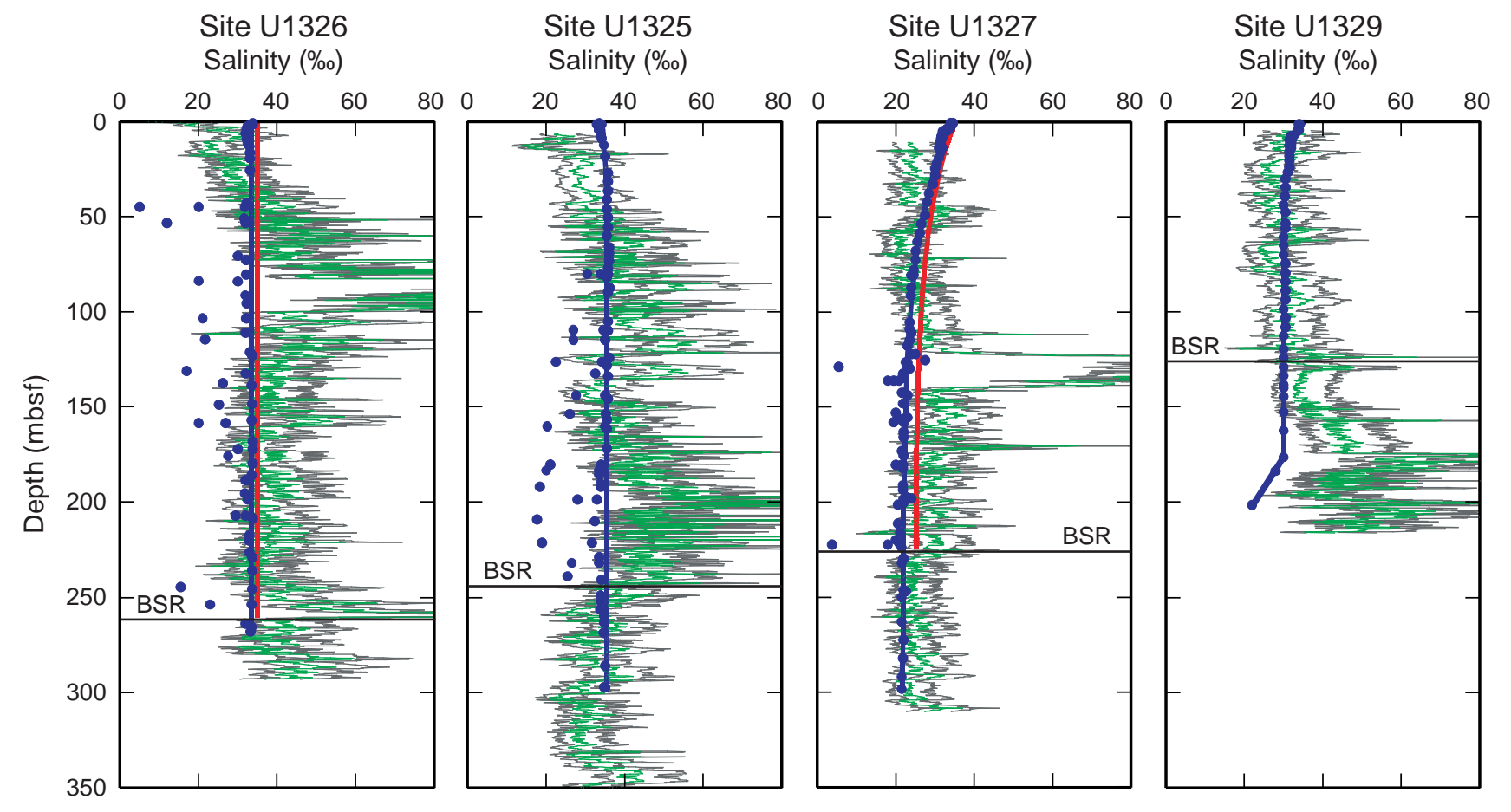


Figure F14. Gas hydrate saturation estimates calculated using core porosity trend and baseline salinity method (black lines), with new baseline salinity profiles for Sites U1326 and U1327. Gray $=1 \sigma$ error from the uncertainty in Archie parameter estimation, blue = density porosity based estimates. BSR = bottom-simulating reflector.

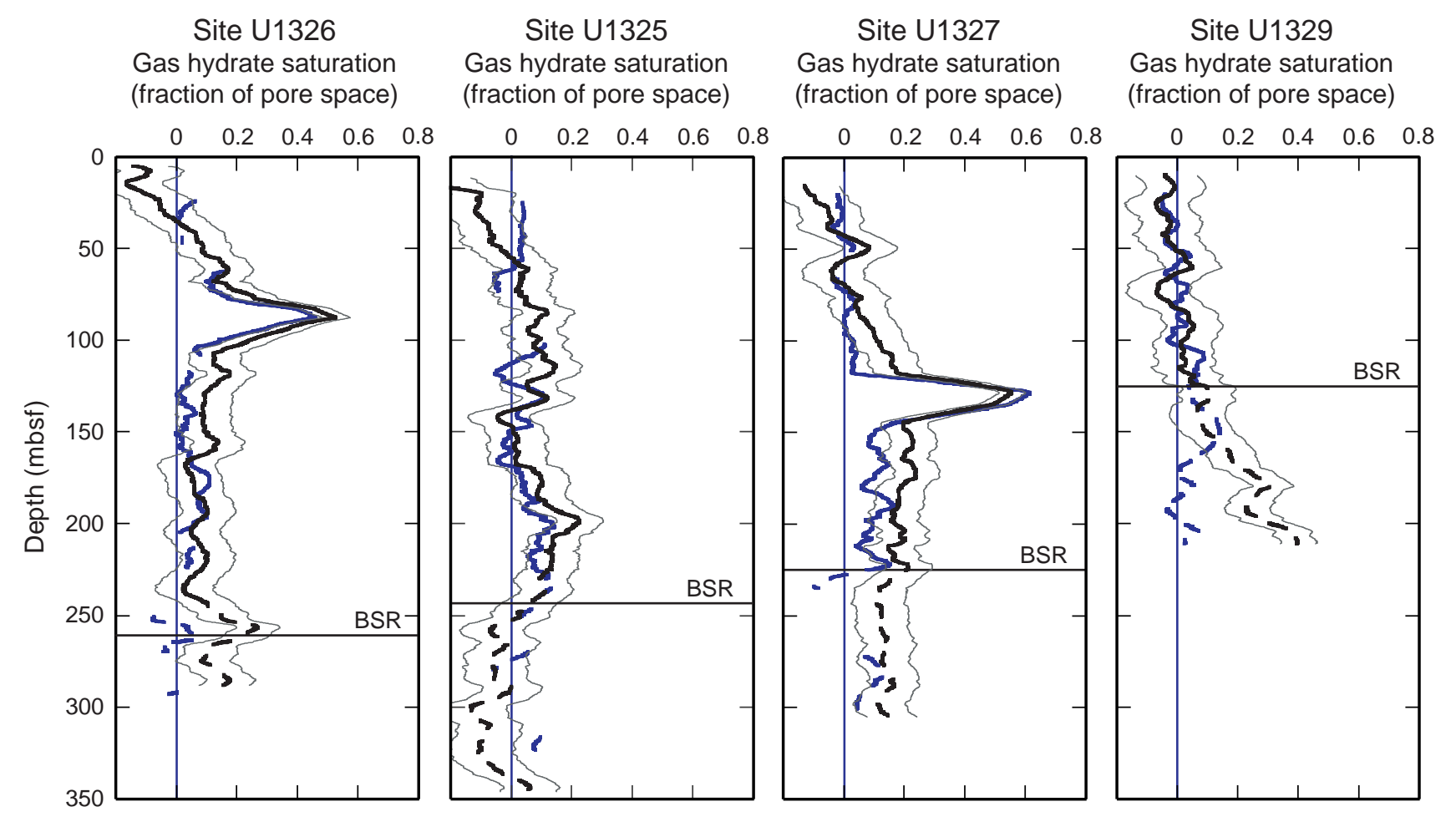

